\begin{tabular}{l} 
2. To: (Receiving Organization) \\
Distribution \\
\hline
\end{tabular}

5. Proj./Prog./Dept./Div.:

Process Chemistry \&

Statistics

8. Originator Remarks:

Process Chemistry \& Statistics Quality Assurance Plan
3. From: (Originating Organization) Analytical Services

6. Cog. Engr.:

H. K. Meznarich
4. Related EDT No.:

NA

7. Purchase Order No.:

9. Equip./Component No.:

NA

10. System/Bldg./Facility:

Process Chemistry Lab

11. Receiver Remarks:
12. Major Assm. Dwg. No.:

NA

13. Permit/Permit Application No.: NA

14. Required Response Date:

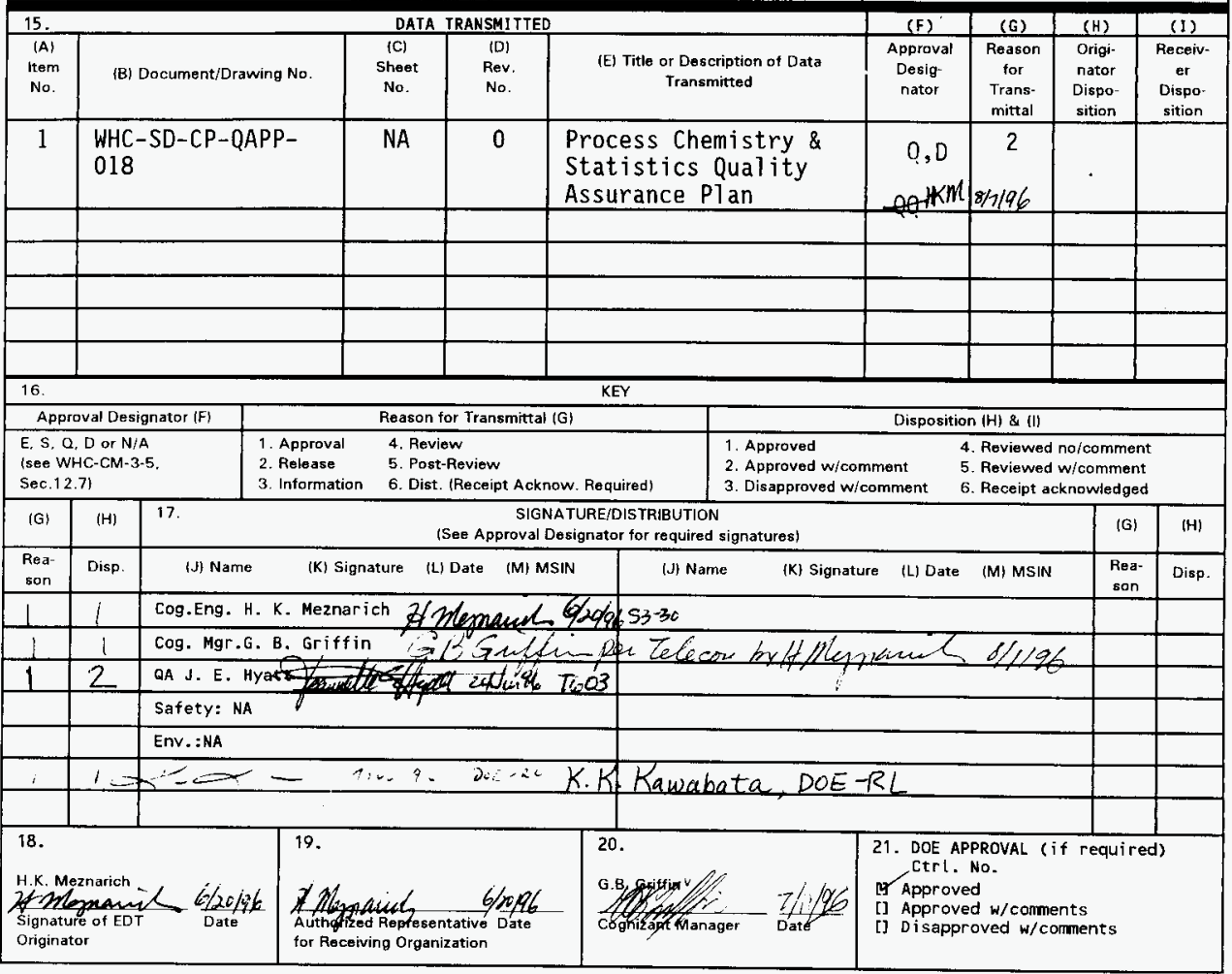




\title{
Process Chemistry \& Statistics Quality Assurance Plan
}

\section{H. K. Meznarich}

WHC, Richland, WA 99352

U.S. Department of Energy Contract DE-AC06-87RL10930

\author{
EDT/ECN: $6 \emptyset 2183$ HC: UC-2070 \\ Org Code: 75730 \\ B\&R Code: EW3130030 \\ Total Pages: 75
}

Key Words: Process chemistry, quality assurance, Process Chemistry \& Statistics

Abstract:

This document provides quality assurance guidelines and quality control requirements for Process Chemistry and Statistics. This document is designed on the bas is of Hanford Analytical Services Quality Assurance Plan (HASQAP) technical guidelines and is used for governing process chemistry activities.

TRADEMARK DISCLAIMER. Reference herein to any specific comercial product, process, or service by trade name, trademark, manufacturer, or otherwise, does not necessarily constitute or imply its endorsement, recomendation, or favoring by the United States Government or any agency thereof or its contractors or subcontractors.

Printed in the United States of America. To obtain copies of this document, contact: WHC/BCS Document Control Services, P.O. Box 1970, Mailstop H6-08, Richtand WA 99352, Phone (509) 372-2420; Fax $(509) \quad 376-4989$
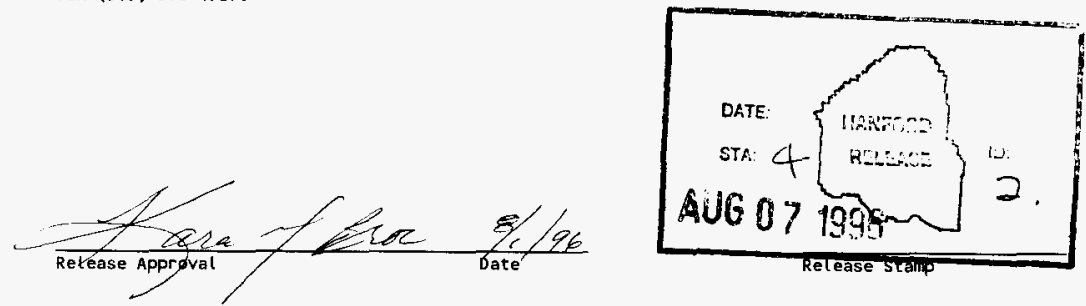

\section{Approved for Public Release}


WHC-SD-CP-QAPP-018 Rev. 0

\title{
PROCESS CHEMISTRY AND STATISTICS QUALITY ASSURANCE PLAN
}

\author{
Prepared by \\ H. K. Meznarich \\ and \\ Process Chemistry \& Statistics
}

Issued by

Analytical Services

For Public Release 
Approvals:
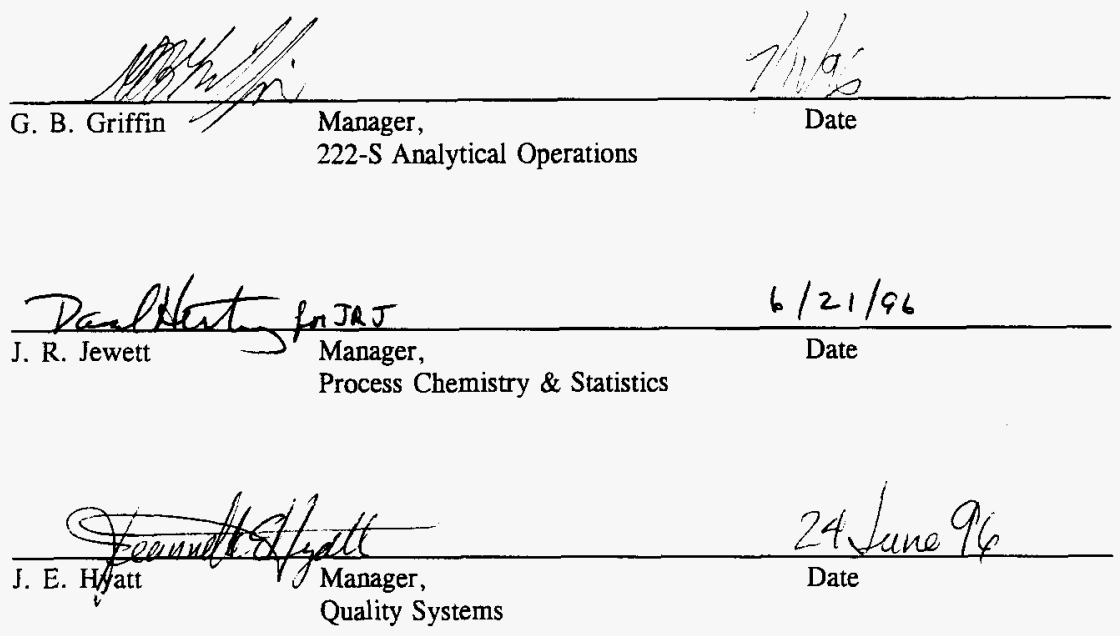


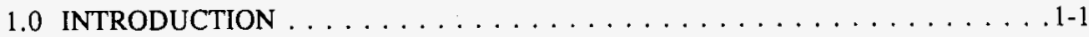

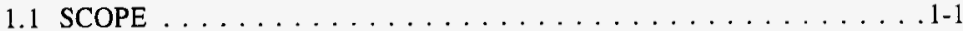

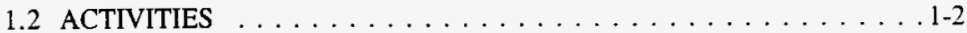

2.0 ORGANIZATION AND RESPONSIBILITY $\ldots \ldots \ldots \ldots \ldots \ldots \ldots \ldots \ldots \ldots$

2.1 Management Policy . . . . . . . . . . . . . . . 2-1

2.2 Organization And Responsibility . . . . . . . . . . . . . . 2-1

2.2.1 Process Chemistry and Statistics . . . . . . . . . 2-2

2.2.2 Other Organizations Supporting The Process Chemistry

and Statistics . . . . . . . . . . . . . 2-2

2.2.3 Process Chemistry's Responsibility for the Quality

Assurance Program . . . . . . . . . . . . . 2-3

2.2.4 Manager Of Process and Chemistry and Statistics . . . . . 2-3

2.2.5 Scientist/Technologist . . . . . . . . . . . . 2-3

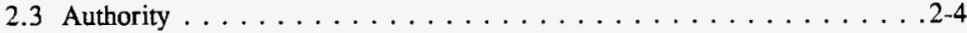

3.0 PERSONNEL QUALIFICATION AND TRAINING $\ldots \ldots \ldots \ldots \ldots \ldots$ 3-1

3.1 Qualification ...................

3.2 Personnel Selection . . . . . . . . . . . . . . . . . . 3.1

3.3 Training Plans . . . . . . . . . . . . . . . . . .

3.4 General Personnel Training . . . . . . . . . . . . . . 3-1

3.4 .1 All Employees . . . . . . . . . . . . . . . 3-1

3.4.2 Developmental Technicians . . . . . . . . . . . . 3-2

3.4.3 Chemists/Scientists . . . . . . . . . . . . . 3-2

3.4 .4 Managers . . . . . . . . . . . . . . . . 3-2

3.4.5 Additional Job-Specific Training . . . . . . . . . 3-2

3.4.6 Continuing Training Requirements . . . . . . . . 3-2

3.4.7 Training Records . . . . . . . . . . . . . 3-2

4.0 QUALITY ASSURANCE OBJECTIVES $\ldots \ldots \ldots \ldots \ldots \ldots \ldots \ldots$ 4-1 $\ldots \ldots \ldots$

4.1 Data Quality Objectives .................. 4-1

4.1.1 System for Notification of Changes in Testing or

Processing Requirements . . . . . . . . . . . . 4-2

4.1 .2 Problem Resolution . . . . . . . . . . . . . . . . 4-2

4.2 Client Data Quality Requirements . . . . . . . . . . . 4-2

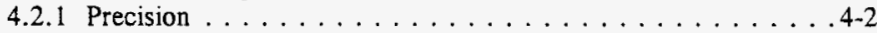

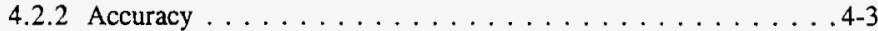

4.2 .3 Comparability . . . . . . . . . . . . . . 4-3

4.2 .4 Completeness . . . . . . . . . . . . . . . .4-3

4.2.5 Representativeness . . . . . . . . . . . . 4-3

5.0 SYSTEMS QUALITY ASSURANCE $\ldots \ldots \ldots \ldots \ldots \ldots \ldots \ldots$. $\ldots \ldots \ldots$

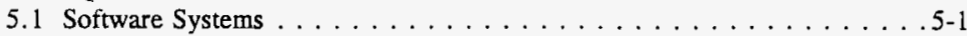

5.1 .1 Control Requirements . . . . . . . . . . . . 5-1

5.1 .2 Acceptance Testing $\ldots \ldots \ldots \ldots \ldots \ldots \ldots \ldots \ldots \ldots$ 
5.1 .3 Backups . . . . . . . . . . . . . . . .5-2

5.1 .4 User's Manuals . . . . . . . . . . . . . . . . . . . . 5-2

5.1 .5 Error Reporting . . . . . . . . . . . . . . . 5-2

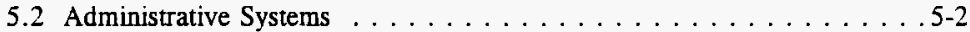

5.3 Physical Facilities Systems $\ldots \ldots \ldots \ldots \ldots \ldots \ldots . \ldots \ldots$

6.0 SAMPLE CUSTODY AND HANDLING $\ldots \ldots \ldots \ldots \ldots \ldots \ldots$ 6-1

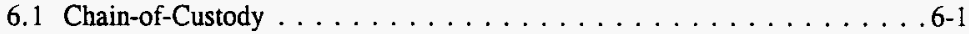

6.2 Sample Receiving Procedure $\ldots \ldots \ldots \ldots \ldots \ldots \ldots \ldots \ldots$ 6-1

6.3 Sample Log-In and Tracking . . . . . . . . . . . . . . . . 6-3

6.4 Laboratory Internal Chain-of-Custody $\ldots . \ldots \ldots \ldots \ldots \ldots . . .6 .3$

6.5 Subsampling and Generating a Chain-of-Custody . . . . . . . . 6-4

6.6 Documentation When Chain-of-Custody is Not Required . . . . . . . . 6-4

6.7 Sample Disposal . . . . . . . . . . . . . . . . 6-5

7.0 CALIBRATION . . . . . . . . . . . . . . . . . . .

7.1 Calibration Of Laboratory Measurement Systems (LMS) . . . . . . . 7-1

7.2 Specifications Of Standards Used In Calibration . . . . . . . . 7-1

7.3 Thermometer and Balances . . . . . . . . . . . . . . 7-2

7.3 .1 Balances . . . . . . . . . . . . . . .

7.3.2 Thermometers . . . . . . . . . . . . . . . 7-3

7.3.3 Calibration Records . . . . . . . . . . . . . 7-3

8.0 LABORATORY PROCEDURES . . . . . . . . . . . . . . . . 8-1

8.1 Procedures and Supporting Documents . . . . . . . . . . . 8-1

8.1.1 Preparation and Review of Supporting Documents . . . . . . . 8-1

8.2 Change Control . . . . . . . . . . . . . . . . . .

8.2.1 Supporting Document Changes $\ldots \ldots \ldots \ldots \ldots \ldots$ 8-2

8.2.2 Procedural Changes . . . . . . . . . . . . . . 8-2

8.3 New Analytical and Process Methods $\ldots \ldots \ldots \ldots \ldots \ldots . . . .8-3$

8.4 Qualification Of Analytical Methods . . . . . . . . . . . . 8-4

8.5 Test Plans and Desk Instructions . . . . . . . . . . . 8-5

9.0 DATA COLLECTION, REDUCTION, AND REPORTING . . . . . . . . . 9-1

9.1 Data Collection . . . . . . . . . . . . . . . . . .9-1

9.2 Data Reduction . . . . . . . . . . . . . . . . .9-2

9.2.1 Significant Figures . . . . . . . . . . . . . .9-2

9.2.2 Rounding-Off Methods . . . . . . . . . . . . . 9-2

9.3 Data Review . . . . . . . . . . . . . . . . . . .9-2

9.4 Data Reporting . . . . . . . . . . . . . . . . . . . .9-3

9.4.1 Data Reporting Documentation . . . . . . . . . . .9-3

9.4.2 Preliminary Reporting . . . . . . . . . . . . . . 9-4

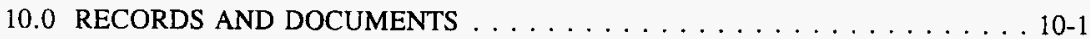

10.1 Generation of Quality Records . . . . . . . . . . . 10-1

10.2 Receipt Control . . . . . . . . . . . . . . 10-1 


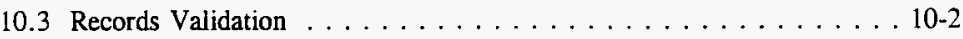

10.4 Correcting Records . . . . . . . . . . . . . . 10-2

10.5 Records Identification and Indexing . . . . . . . . . . 10-2

10.6 Maintenance and Retention of Records . . . . . . . . . . 10-2

10.6.1 Access Control . . . . . . . . . . . . . . . 10-3

10.6.2 Replacement, Restoration, or Substitution of Records . . . . 10-3

10.6.3 Records Turnover to Client . . . . . . . . . . . . . . . 10-3

11.0 QUALITY CONTROL $\ldots \ldots \ldots \ldots \ldots \ldots \ldots \ldots \ldots \ldots \ldots \ldots \ldots \ldots \ldots$

11.1 Materials . .......................

11.1.1 Chemicals ...................11-1

11.1 .2 Reagents . . . . . . . . . . . . . . . . .11-1

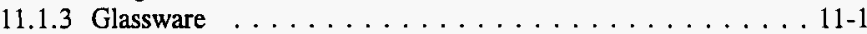

11.2 Design . . . . . . . . . . . . . . . . . . .

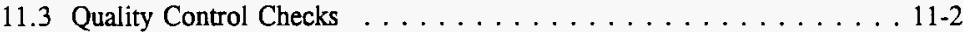

11.3.1 Mass Balance/Charge Balance . . . . . . . . . . . 11-2

11.3.2 Relationship of Samples in a Set . . . . . . . . . . 11-3

11.3.3 Blanks, Duplicates, Spikes . . . . . . . . . . . 11-4

11.4 Peer Review . . . . . . . . . . . . . . . . . . . 11-4

12.0 PROCEDURES TO ASSESS DATA QUALITY $\ldots \ldots \ldots \ldots \ldots$. . . . . . . .

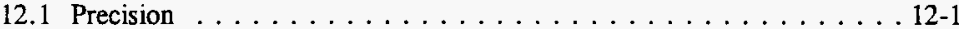

12.1.1 Relative Standard Deviation . . . . . . . . . . 12-1

12.1.2 Relative Percent Difference . . . . . . . . . . . . . 12-1

12.2 Accuracy . . . . . . . . . . . . . . . . . 12-2

12.2.1 Method Accuracy Based on Sample Spike . . . . . . . . 12-2

12.2.2 Method Accuracy Based on Standard . . . . . . . . . . 12-2

12.3 Measures of Agreement . . . . . . . . . . . . . . . 12-2

12.3.1 Percent Difference . . . . . . . . . . . . . . . . 12-2

12.3.2 Bias . . . . . . . . . . . . . . . . . 12-3

12.4 Detection Limit Considerations . . . . . . . . . . . . . 12-3

12.4.1 Method Detection Limit . . . . . . . . . . . . . . . 12-3

12.4.2 Instrument Detection Limit . . . . . . . . . . . . . 12-4

12.4.3 Estimated Quantitation Limit . . . . . . . . . . . . 12-4

13.0 AUDITS . . . . . . . . . . . . . . . . . . . . . . . . . 13-1

13.1 Management Audits . . . . . . . . . . . . . . . . 13-1

13.2 Data Quality Audits . . . . . . . . . . . . . . . . 13-1

13.3 External Audits . . . . . . . . . . . . . . . . . 13-2

14.0 PREVENTIVE MAINTENANCE $\ldots \ldots \ldots \ldots \ldots \ldots \ldots \ldots \ldots$ 14-1 $\ldots \ldots \ldots$

15.0 CORRECTIVE ACTION AND CONTINUOUS QUALITY

IMPROVEMENT . . . . . . . . . . . . . . . . . 15-1

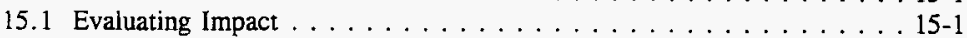

15.2 Recurring Conditions Adverse To Quality . . . . . . . . 15-2 
15.3 Trend Analysis . . . . . . . . . . . . . . . 15-2

15.4 Root Cause Analysis . . . . . . . . . . . . . 15-2

15.5 Continuous Quality Improvement $\ldots \ldots \ldots \ldots \ldots \ldots \ldots \ldots$

16.0 QUALITY ASSURANCE REPORTS $\ldots \ldots \ldots \ldots \ldots \ldots \ldots \ldots \ldots$ 16-1

17.0 DATA VALIDATION $\ldots \ldots \ldots \ldots \ldots \ldots \ldots \ldots \ldots \ldots \ldots \ldots \ldots \ldots \ldots \ldots .17$

18.0 PROCUREMENT CONTROLS $\ldots \ldots \ldots \ldots \ldots \ldots \ldots$ 18-1

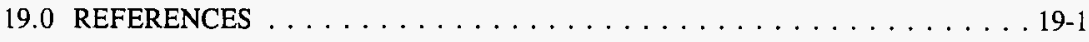

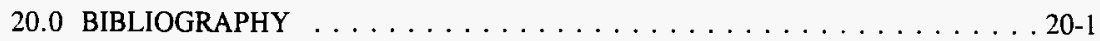

APPENDIX A. QUALITY ASSURANCE INDEX $\ldots \ldots \ldots \ldots \ldots \ldots$ A-1

APPENDIX B. ANALYTICAL OPERATIONS ORGANIZATION AND QUALITY INTERFACE $\ldots \ldots \ldots \ldots \ldots \ldots \ldots \ldots \ldots$ B-1

APPENDIX C. GLOSSARY $\ldots \ldots \ldots \ldots \ldots \ldots \ldots \ldots \ldots$ C-1

\section{TABLE}

Table 5.1. Physical Facilities $\ldots \ldots \ldots \ldots \ldots \ldots \ldots \ldots \ldots \ldots$. . . . . . . . . 
WHC-SD-CP-QAPP-018 Rev. 0

\section{Acronym List}

\begin{tabular}{|c|c|}
\hline$\% \mathrm{D}$ & percent difference \\
\hline$\% \mathrm{R}$ & percent recovery \\
\hline AA & atomic absorption \\
\hline $\mathrm{AO}$ & 222-S Analytical Operations \\
\hline AS & Analytical Services \\
\hline CFR & U.S. Code of Federal Regulations \\
\hline $\mathrm{CM}$ & controlled manual \\
\hline DOE & U.S. Department of Energy \\
\hline DQO & data quality objective \\
\hline $\mathrm{ECN}$ & Engineering Change Notice \\
\hline EDT & engineering data transmittal \\
\hline EPA & U.S. Environmental Protection Agency \\
\hline EQL & estimated quantitation limit \\
\hline ETS & Engineering \& Technology Services \\
\hline GEA & gamma energy analysis \\
\hline GIC & General Inventory Catalogs \\
\hline HASQAP & Hanford Analytical Services Quality Assurance Plan \\
\hline HATS & Hanford Action Tracking System \\
\hline HLAN & Hanford Local Area Network \\
\hline IC & ion chromatography \\
\hline ICP & inductiveiy coupled plasma (spectrometer) \\
\hline IDL & instrument detection limit \\
\hline IRM & Information Resource Management \\
\hline LA & Laboratory Analytical (procedure) \\
\hline $\mathrm{LC}$ & Laboratory Computer (procedure) \\
\hline LIMS & Laboratory Information Management System \\
\hline LMS & Laboratory Measurement System \\
\hline LO & Laboratory Operating (procedure) \\
\hline LOI & letter of instruction \\
\hline $\mathrm{LT}$ & Laboratory Technology (procedure) \\
\hline MDL & method detection limit \\
\hline NIST & National Institute of Standards and Technology \\
\hline OJT & on-the-job training \\
\hline PCA & Procedure Change Authorization \\
\hline PCS & Process Chemistry and Statistics \\
\hline PM\&I & Program Management \& Integration \\
\hline PNNL & Pacific Northwest National Laboratory \\
\hline PRAF & procedure review and approval form \\
\hline QA & quality assurance \\
\hline QAPP & Quality Assurance Program Plan \\
\hline QAPjP & Quality Assurance Project Plan \\
\hline $\mathrm{QC}$ & quality control \\
\hline QS & Quality Systems \\
\hline RCRA & Resource Conservation and Recovery Act \\
\hline
\end{tabular}


RHA-MIS

RIDS

RL

RPD

RSD

SD

SV

TC

TD

TMX

TWRS

VOA

WHC
Records Holding Area - Management Information System Records Inventory Disposition Schedule U.S. Department of Energy, Richland Operations Office relative percent difference relative standard deviation supporting document semivolatile (organics) to contain to deliver Training Matrix Tank Waste Remediation Systems volatile organic analyte (analysis) Westinghouse Hanford Company 


\subsection{INTRODUCTION}

This quality assurance plan provides guidance to meet the requirements of Westinghouse Hanford Company Quality Assurance Program and Implementation Plan. Implementation of Title 10 Code of Federal Regulations Part 830.120 (WHC-SP-1131) and the objectives of the Quality Assurance Manual (WHC-CM-4-2), especially Section QI 2.1 of that manual, "Quality Assurance Program Planning -- Project-Type Activities." The quality assurance elements required in the Guidelines and Specifications for Preparing Quality Assurance Program Plans (QAMS-004) and Interim Guidelines and Specifications for Preparing Quality Assurance Project Plans (QAMS-005) from the U. S. Environmental Protection Agency were incorporated to the extent applicable in this document. A quality assurance index is provided as Appendix A.

The laboratory work performed by Process Chemistry and Statistics falls into three general categories -- (1) testing of chemical processes, (2) characterization of materials, and (3) development of materials characterization methods. This document specifies the quality assurance procedures and requirements only for the first of these categories -- process testing. The other two types of activities, those dealing with characterization of materials, follow the quality assurance requirements in the 222-S Laboratory Quality Assurance Plan (WHC-SD-CP-QAPP-016).

Chemical processes are conducted to separate chemical components from each other or to change the properties of a material in some desired way. At Hanford, the materials are often hazardous wastes, which may or may not be radioactive, and the process is intended to separate waste components from each other or to improve the storage properties of the material. This document provides the basic quality assurance procedures and principles used by PCS in the conduct of testing the chemical processes in use or contemplated for use at Hanford. Small-scale laboratory testing of a contemplated process is usually necessary to determine whether the process merits the expense of building a large-scale processing facility. Testing of a process actually in use is sometimes required to correct process deficiencies or improve process efficiency.

Process testing normally follows a sequence a listed below:

- Planning

- Preparation of test facility

- Procurement of test materials (sampling)

- Characterization of the test materials

- Simulation of the process (or of some step in the process)

- Characterization of the materials resulting from the test.

In many testing projects, these steps are performed iteratively. The results obtained in certain steps may require looping back to previous steps, perhaps using different parameters. Some of the activities in this list may be assigned to personnel outside PCS. For example, the characterization steps are often performed by other Analytical Operations personnel (according to the requirements in the WHC-SD-CP-QAPP-016). When outside assistance is 
used, the PCS principal investigator shall ensure that the requirements of this quality assurance plan are met.

This document provides basic requirements to ensure that test results are meaningful; i.e., the results are a valid basis for making management and engineering decisions. Because the processes that may be tested and the questions to be solved are so diverse, it may be necessary from time to time to deviate from the principles stated in this document. In those circumstances, the deviations shall be clearly stated in test plans and reports, so that data users are fully cognizant of the quality and limitations of the data. 
WHC-SD-CP-QAPP-018 Rev. 0

\subsection{ORGANIZATION AND RESPONSIBILITY}

The charters and responsibilities for each organizations are published in Section 2 of WHC-CM-5-4, Laboratories Administration.

\subsection{Management Policy}

The policy of the TWRS Characterization Project and Process Chemistry and Statistics management is to direct activities in a manner that ensures the results meet or exceed the customer's requirements and provides supporting documentation. This policy shall be implemented through the following:

- Personnel are responsible for the quality of their own work. Personnel shall check their supplies and plans to ascertain that the items are correct and suitable for use.

- All levels of management accept responsibility for their organization's activities and are held accountable for achieving quality.

- Management provides adequate resources and budget to support effective quality assurance practices that fulfill the customer's program goals and performance objectives.

- Management provides facilities, instruments, support equipment, and materials required to meet the customer's current and projected requirements.

- PCS personnel shall have acceptable qualifications and training for their specific job assignments.

- Documentation is controlled and maintained in a manner that ensures that PCS can demonstrate compliance to customers' requirements.

- Quality is achieved and improved by planned, systematic and self-assessments, and measured actions.

- Quality control data document the accuracy and precision performance of instruments and methods.

\subsection{Organization And Responsibility}

The PCS organization reports to 222-S Analytical Operations. The 222-S Analytical Operations organization reports to Analytical Services (AS). The AS is under the TWRS Characterization Project to support TWRS characterization activities. A descriptive breakdown of these organizations is provided in Appendix B. The PCS laboratory is located in the 222-S Analytical Laboratory complex. 
If changes in organizational structure occur, which do not reflect a change in the overall laboratory functions, this QA plan shall remain valid. Information corresponding to such organizational changes shall be incorporated in the next revision of this QA plan.

\subsubsection{Process Chemistry and Statistics}

The PCS is responsible for sample preparation, process and analytical methods development, and physical testing measurements for various projects on site. Process development and testing performed by the PCS includes working with clients to develop test plans, defining data quality objectives for the projects, as well as scheduling and defining deliverables. In addition, PCS often is responsible for technical consultation, data interpretation, and generation of summary reports.

\subsubsection{Other Organizations Supporting Process Chemistry and Statistics}

The following services are provided by other organizations in order to achieve a quality assurance program in support of PCS activities.

\section{A. 222-S Analytical Operations}

The Analytical Operations (AO) organization is responsible for providing analytical services in support of TWRS characterization activities, Westinghouse Hanford Company (WHC) environmental and waste management activities, and for routine laboratory analyses and services.

Shift Operations is responsible for calibrating analytical measurement systems (when applicable), performing analyses, and generating, calculating, and reviewing data.

Hazardous Material and Control is responsible for controlling and disposing of the hazardous waste generated in the laboratory.

Building Operations is responsible for maintaining and operating the laboratory facilities.

\section{B. Program Management \& Integration}

Functions of Program Management \& Integration (PM\&I) include program management services, serving as a single-point-of-contact for laboratory customers, and maintaining a continuously updated laboratory master schedule. Additional services provided include records management, administration of laboratory procedures and the WHC-CM-5-4 manual, and maintenance of the Laboratory Technical Information Center.

Program Support is responsible for coordinating sample scheduling and data quality objective(s) between the laboratory and the client. Program Support is also closely associated with the Characterization Technical Basis organization from the TWRS 
Characterization Project for defining analysis requirements, scheduling, and data reporting. They are also responsible for laboratory quality control and preparing data packages.

\section{Engineering \& Technology Services}

The Engineering \& Technology Services (ETS) organization provides engineering services, laboratory support, chemical standards services, information and automated data processing systems, AS maintenance, regulatory compliance, and work control.

Information Systems is responsible for developing and maintaining the automated data processing system (e.g., LABCORE). The Standards Laboratory is responsible for procuring and preparing chemicals, standards, and reagents. The Laboratory Engineering organization is responsible for calibrating balances and conducting instrument preventive maintenance when requested. Laboratory Support is responsible for the mandatory training program and maintaining the Hanford Action Tracking System (HATS).

The AS Maintenance and Work Control is responsible for work control and material procurement and control.

\section{Quality Systems}

The Quality Systems (QS) organization provides quality assurance oversight and performs annual audits of PCS.

\subsubsection{Process Chemistry's Responsibility for the Quality Assurance Program}

The manager of PCS is responsible for the overall quality of tests performed and suitability of objectives requested.

Personnel at each level that are involved in generating data or providing test or process evaluation are responsible for knowing the content of the laboratory quality assurance plan and upholding the standards. Each person shall carry out his/her daily tasks in a manner consistent with the policy expressed in this manual and in accordance with the laboratory procedures.

\subsubsection{Manager Of Process and Chemistry and Statistics}

The manager of Process Chemistry and Statistics is responsible for all PCS laboratory activities, for ensuring implementation of this Quality Assurance program, and shall encourage the cooperation of laboratory personnel in this program.

\subsubsection{Scientist/Technologist}

The scientist has the responsibility for carrying out the daily QC activities, maintaining quality standards, and ensuring a smooth flow of work. 
Responsibilities of the principal investigator on each project include the following:

- Ensure the QA requirements for the project are defined and implemented

- Oversee and/or implement project QA/QC requirements

- Oversee and/or coordinate the performance of program activities

- Oversee/initiate corrective action

- Generate and summarize reports that include quaiity control issues.

- Report quality problems to management

- Evaluate and verify data quality.

\subsection{Authority}

Personnel involved in the generation of data are responsible for the QA/QC program. In addition, such personnel have the authority to initiate the following appropriate actions:

- Prevent reporting results from a measurement system that is out of control; prevent further sample analysis and reporting until corrective action has been completed

- Identify any laboratory method or procedure that poses quality problems

- Provide solutions to problems through designated channels and monitor effectiveness

- Initiate a stop-work order where safety, serious quality, or health conditions exist. 


\subsection{PERSONNEL QUALIFICATION AND TRANNING}

\subsection{Qualification}

The PCS group considers education, experience, and training as components of personnel qualifications. All personnel must meet or exceed minimum qualification requirements for their position. Minimum education and experience requirements are stated in WHC-CM-5-4, Section 4.3, Table 1.

\subsection{Personnel Selection}

Employee seiection and job assignment are based upon an evaluation of the requirements of the position and the candidates education, training, and previous experience. Only those candidates meeting or exceeding minimum requirements are selected.

\subsection{Training Plans}

The PCS employees have an employee-specific training plan, determined by their immediate supervisor using the Training Matrix Program system (TMX). The training plan includes job-specific required training courses, required on-the-job training (OJT), and remedial training to correct performance deficiencies. The training plan also includes optional development including training from courses offered by AS, AO, WHC, off-site seminars, symposia and short courses, other work-related training, or professional development activities, as appropriate.

In order to meet the formal training requirements in WHC-CM-5-4, Section 4, PCS provides continuing improvement in the awareness and proficiency of employees within the framework of the 222-S training matrix (as described in WHC-SD-CP-QAPP-016, Section 3.0, Personnel, Qualification and Training). Where practical, access to other WHC, as well as off-site training and professional development opportunities, is encouraged. In addition, in development of methods and non-routine process evaluation, a variety of lessons are learned. These lessons may be documented on internal memorandum addressed to the customer, or in general correspondence through laboratory management so that they may be implemented in subsequent practices.

\subsection{General Personnel Training}

\subsubsection{All Employees}

The PCS personnel are oriented to the mission and objectives of the laboratory, the general requirements of HASQAP, and the individual's responsibility within their organization to follow an established QA plan. 
The PCS scientists and technicians are trained in basic facility orientation, general safety training, building emergency procedures, and self-monitoring. Training requirements described in this section are detailed in WHC-CM-5-4, Section 4.5. In addition to these mandatory training requirements, specific training related to each job category is described in the following sections. Statisticians generally are not 222-S Laboratory workers and are exempt from 222-S Laboratory-specific training requirements.

\subsubsection{Developmental Technicians}

Developmental technologist training includes initial laboratory familiarity progressing to more specific training with laboratory procedures and company-specific training for their work assignment.

\subsubsection{Chemists/Scientists}

Chemist/scientist training includes operational specific procedures for working in the laboratory and procedure author training.

\subsubsection{Managers}

The roles and responsibilities as a laboratory manager to lead, direct, and motivate people are emphasized. Manager training also includes familiarization with the various safety, engineering, and work control systems in use at the 222-S Laboratory.

\subsubsection{Additional Job-Specific Training}

Additional job-specific course work may be required to develop and/or maintain proficiency in areas of instrument operation, hot cell operation, sample preparation, maintenance, building operations, shift supervision, waste management, facility engineering, and OJT instruction.

\subsubsection{Continuing Training Requirements}

Controlled manual WHC-CM-5-4, Section 4.5, contains retraining requirements for each course title referenced above. These retraining requirements are typically either annual or biennial. Retraining requirements are called out in the individual annual training plan, by routine requalification tickler from the training department, or by specific training identified through the continuous improvement program. Continuing training programs are structured around specific position needs and are designed to enhance personnel proficiency.

\subsubsection{Training Records}

Management maintains a personnel file for each employee. This file documents educational background, completed company training courses, performance issues, other external trainings, symposia, or conferences attended. Exempt employees have current resumes/competence records in these files. A "Training Completion Record Form C - 
WHC-SD-CP-QAPP-018 Rev. 0

Offsite Training Verification" (A-6000-821) must be submitted by the attendee on completion of external training outside the WHC Training Department. The attendee is responsible for forwarding the completed form to Training Records.

Annual training plans are available in the TMX. 
WHC-SD-CP-QAPP-018 Rev. 0

\subsection{QUALITY ASSURANCE OBJECTTVES}

\subsection{Data Quality Objectives}

Quality assurance (QA) objectives provide a set of recognized parameters to monitor performance of an analytical measurement system or a process test. Establishment of data quality objectives criteria can be achieved based on the data usage by the client, process knowledge, and historical information.

The PCS policy is to have a written agreement (test plan) or letter of instruction (LOI) based upon client project data quaiity objectives. The test plan should be based on client data quality objectives (DQOs) or criteria agreed upon between the client and PCS. The test plan may be prepared by PCS.

Testing designs should be discussed with statisticians before proceeding with the work. Analytical results that are generated by the 222-S Laboratory are used to evaluate the outcome of these testing designs. Data quality of these analytical results from 222-S Laboratory is ensured by compliance with WHC-SD-CP-QAPP-016.

The test plan or letter of instruction committing resources (e.g., planning documents, time and dollar estimates of work to be completed) requires PCS management approval.

In the agreement, the following information shall be provided when appropriate:

- Applicable regulatory requirements

- Process knowledge, sample source, and sample conditions known to the client that could impact laboratory worker's safety

- Handling of radioactive samples in the transport process and in the laboratory

- Estimated number and matrix of samples

- Sample handling relative to specific sample or matrix and step by step processing and/or sample preparation requirements

- Analysis methods and analyte lists for sample analysis

- Quality control sample (e.g., frequency, type [e.g., duplicate, spikes, and/or blanks]), and acceptance criteria that must be reported

- Expected date of sample receipt, sample preservation, delivery methods, storage and container types and volumes, and holding times by method

- Format and content of reports 
- Requested turnaround times (from date of sample receipt to date of data delivery) in the laboratory

- Name, address, telephone number of client, laboratory contacts responsible for the project, and information to establish electronic data transfer

- Return of samples or disposition of waste.

\subsubsection{System for Notification of Changes in Testing or Processing Requirements}

A communication system is established for notification of changes in testing or processing requirements between the client, management, and/or project scientist (or a team of scientists). The notification method may include meeting minutes, cc:Mail ${ }^{1}$, memo, or letter of instruction. Written instructions/minutes shall be prepared and distributed by the originator and to appropriate persons with lead responsibility. Copies of communications should be posted in the controlled project notebook.

\subsubsection{Problem Resolution}

The laboratory notifies the client when situations such as anomalies and noncompliances occur. On-going communication established between the client and project scientist is then aimed towards establishment of clear understanding of the process problem and resolution. Resolution shall be coordinated at the chemist or line manager level. Corrective action shall be initiated in a reasonable time frame and shall be documented in the project notebook.

\subsection{Client Data Quality Requirements}

Five parameters are often used by the client to define project or analytical data quality requirements. These include precision, accuracy, completeness, comparability, and representativeness. Of these, the precision, accuracy, and representativeness have direct impacts on analytical data quality. The client is responsible for ensuring that adequate sample material is available and that appropriate sampling techniques are administered in order to meet their data quality objective(s). The PCS laboratory is responsible for using proper sample handling protocols to ensure sample integrity. In addition, PCS will consult with clients to ensure sample representativeness, wherever possible.

\subsubsection{Precision}

Precision in process testing and measurements represents a measure of the degree of reproducibility of measurements under prescribed similar conditions. Precision is determined by means of replicate measurements of specific process parameters that define the systems or process. Determination of the relative standard deviation (RSD) of the data set provides a

\footnotetext{
${ }^{1} \mathrm{cc}$ :Mail is a trademark of Lotus Development Corporation.
} 
measure of how closely the process is operating within specifications for a particular process parameter. Acceptable processes criteria will be established for each process tested. Agreement on process criteria will be made between PCS and the customer.

\subsubsection{Accuracy}

Accuracy represents the degree to which a measurement agrees with an accepted reference value. The agreement may include bench data as compared to expected scale-up values or historical data based on trends. Accuracy may be difficult to define for a specific process where a true (reference) value is not known. However, when expected values are available, measurements may be made and compared to those expected for the pilot plant or process. In this way, an estimation of accuracy may be determined based on the assumption that the expected value is the true value. Expected values and results are included in test plans as agreed upon by the responsible scientist, statistician and/or customer.

\subsubsection{Comparability}

Comparability is the confidence with which one data set can be compared to another. In order for a data set to be comparable, similar precision, accuracy, and sensitivity of measurements used must be achieved. In addition, samples must be representative of those used in the process (see section 4.2.5). Factors such as process variables, analytical method selected for testing results and laboratory data quality, detection limits or uncertainty, precision, accuracy, and matrix effects should be taken into consideration when data are to be compared. Process controls or standard specifications should be included when comparing different results.

\subsubsection{Completeness}

Completeness is a measure of the amount of usable data obtained from a system or process compared to the total amount of data requested. In some cases, data as required by the customer may not meet the customer's expectations or needs. However, the data may still be usable as qualitative information for defining a process or the effects of a process parameter change. Therefore, a clear definition of completeness that includes the use of qualitative analysis when other requirements are not met should be agreed upon by PCS and the customer. In addition, sample analysis may be prioritized between PCS and the customer to provide the maximum data value for the cost of analysis. The customer and PCS must agree with the amount of data required to describe the system adequately and provide alternatives to measurements if they are known.

\subsubsection{Representativeness}

Representativeness is the degree to which a parameter mimics a real process, a sample defines the system from which it is taken, or the data accurately and precisely represent a population, parameter variation at a specific sampling point, a process condition, or an environmental condition. Representativeness of a population or an environmental condition 
depends heavily on sampling. Methods should be assessed after accumulation of sufficient data to represent identical populations.

All samples received by PCS will be handled and prepared in order to maintain sample integrity and representativeness. Particular attention will be given to sample homogeneity and sub-sampling in order to ensure samples are representative of the original material in its as sampled environment. When a sample seems questionable based on multiple phases, or unexpected appearance, the customer will be notified. Method changes will be noted in correspondence between the customer and these changes will be posted in the laboratory notebook for the project. 


\subsection{SYSTEMS QUALITY ASSURANCE}

\subsection{Software Systems}

Laboratory software systems can be separated by application into two categories: administrative and technical. Administrative software systems manage the work flow or monitor performance against administrative requirements. Examples of administrative software systems are those that control sample tracking, procedure control, training, and reporting. Technical software systems control laboratory systems, and accumulate and reduce data. Examples of technical software systems are those that provide instrument interface, calculations, calibration control, and control charts. The PCS group depends on other organizations for administration of software maintenance. However, some technical software, which is commercially available, is maintained within the group by a software specialist.

\subsubsection{Control Requirements}

Software control requirements applicable to both commercial and laboratory-developed software shall be developed, documented, and implemented. Software systems shall be protected from unauthorized or inadvertent changes.

Software systems shall be documented under configuration control. For laboratory-developed software systems, a copy of the original program code shall be maintained. Changes should include a description of the change, authorization for the change, and test data that validates the change. Configuration control and acceptance test data shall be maintained for commercial software packages. Authorization for changes are the responsibility of the scientist in charge of the system.

The following documents govern laboratory software system configuration control:

- WHC-SD-WM-CM-002, Configuration Management Plan for LABCORE Program

- WHC-CM-5-4, Sections 8.3 and 8.6 for projects outside the scope of the LABCORE program as well as for any project that does not have a specific configuration management plan in place.

\subsubsection{Acceptance Testing}

Software systems shall be tested for acceptance when installed, after changes, and periodically during use. The frequency of the test shall be based on the potential for adverse impact on the laboratory and the ease in which changes can be made to the computer code. Testing may consist of manually performing calculations, checking against another software system that has been previously tested, comparing output with previous output, or by analyzing standards. A graded approach is used for the in-house developed spreadsheet using a well-established commercial database software. If the spreadsheet is only used once for data calculation, the author shall verify the accuracy of the spreadsheet by testing the 
calculation manually. This verification should be performed by an independent reviewer who is familiar with the calculations included in the spreadsheet.

Documentation of the testing shall include printouts of the data or results from data generated by the software for comparison, the name of the person performing the test, and the date the test was performed. The version and manufacturer of the software shail be documented.

\subsubsection{Backups}

Both software and data shall be backed up. The frequency of backup shall be based on the amount of data and the impact of the loss of data or software on the organization.

\subsubsection{User's Manuals}

Laboratory computer (LC) procedures are issued when appropriate for an application. If programs or applications for projects outside the scope of the LABCORE system are small or straight forward, a controlled manual or special training is not required (see WHC-CM-3-10, Software Practices, Section SP-3.4, "Small Job Development").

\subsubsection{Error Reporting}

Data management software errors found during use are immediately reported to the system administrator of software. Errors and corrective actions shall be documented.

\subsection{Administrative Systems}

Westinghouse Hanford Company has established an administrative control system based on a hierarchy of controlled manuals (CM). These manuals provide documented interpretation of DOE orders and procedures for implementation. The 222-S Laboratory works to the administrative policies and directions published in Westinghouse Hanford Company Controlled Manuals (WHC-CM) In the WHC-CM system, a hierarchy exists in which Level I manuals provide direction from the President for implementation of key policy and administrative actions, Level II manuals are issued by company organizations for implementation of broadly applicable activities based on specific DOE orders (e.g., safety, quality assurance, and purchasing), and Level III manuals are provided for personnel at the working level, providing additional information not found in higher level documents. In addition to the administration directions listed in manuals, laboratory procedures are used for specific activities.

Controlled manual WHC-CM-5-4, Laboratories Administration, is a Level III manual that provides documentation describing and directing laboratory activities not sufficiently covered in Level II documents. 
The following list identifies the documents that provide laboratory personnel with approved directions for various activities:

- Organization charts are published by the Director of Analytical Services

- Procurement controls are in the Level II manual WHC-CM-2-1, Procurement Manual and Procedures

- WHC-CM-5-4, Laboratories Administration

- Sample and waste disposal instructions are found in the series of laboratory procedures numbered LO-100-nnn

- Sample receiving and custodianship instructions are found in the series of laboratory procedures numbered LO-090-nnn.

\subsection{Physical Facilities Systems}

The PCS Laboratory is physically located inside the 222-S Laboratory. Supporting document WHC-SD-CP-HIE-001 describes facilities orientation and operation, hazards identification and evaluation, and operational safety limits. Table 5.1 lists physical facilities in the 222-S and PCS Laboratories.

The 222-S Laboratory is a two-story building with its main work areas on the first floor and a section of the basement. The 222-S facility has emergency power service for ventilation and lighting. Critical computer systems are protected by uninterruptable power supplies.

Laboratory work areas are maintained at negative pressure with respect to atmosphere using a once through ventilation system. The air supply system is designed to distribute filtered air into the laboratory work areas. Samples are stored according to type of analysis, activity level, and to prevent cross contamination. Refrigerator temperature is monitored and maintained at the specified level. 
WHC-SD-CP-QAPP-018 Rev. 0

Table 5.1. Physical Facilities

\begin{tabular}{|l|c|c|c||}
\hline \multicolumn{1}{|c|}{ Facility } & 222-S & $\begin{array}{c}\text { MO346 and } \\
\text { MO947 }\end{array}$ & 222-SA \\
\hline Sample Receiving Area & Yes & No & Yes \\
\hline Sample Storage Area & Yes & No & No \\
\hline Hot Cell for Sample Extrusion & Yes & No & No \\
\hline Standard Preparation & Yes & No & Yes \\
\hline $\begin{array}{l}\text { Sample Preparation } \\
\text { Organic: VOA }{ }^{2}, \text { SV }\end{array}$ & Yes & No & No \\
\hline $\begin{array}{l}\text { Sample Preparation/Extraction } \\
\text { Inorganic: ICP, AA }\end{array}$ & Yes & No & No \\
\hline Wet Chemistry & Yes & No & Yes \\
\hline Preparation for Radiochemistry & Yes & No & No \\
\hline Counting Room & Yes & No & No \\
\hline Chemical Storage & Yes & No & Yes \\
\hline Shipping Area & Yes & No & Yes \\
\hline Waste Storage & Yes & No & Yes \\
\hline Flammable Gas Storage & Yes & No & Yes \\
\hline Non-Flammable Gas Storage & Yes & No & No \\
\hline Lunch Room & Yes & Yes & Yes \\
\hline Offices & Yes & Yes & Yes \\
\hline Change Room & Yes & No & No \\
\hline Equipment & Yes & No & Yes \\
\hline Equipment Storage & No & Yes \\
\hline Quality Assurance Records Storage & Yes \\
\hline
\end{tabular}

\footnotetext{
${ }^{2} \mathrm{VOA}=$ volatile organic analyte (analysis)

${ }^{3} \mathrm{SV}=$ semivolatile (organics)

${ }^{4} \mathrm{AA}=$ atomic absorption
} 


\subsection{SAMPLE CUSTODY AND HANDLING}

\subsection{Chain-of-Custody}

The PCS Laboratory is restricted to authorized personnel only. Admission to the 222-S Laboratory area requires special badging. The entire 222-S Laboratory and the 222-SA PCS Laboratory are considered secured areas. During the day, access doors at 222-S Laboratory are either monitored by personnel or locked if personnel are not present. Doors are locked during the night.

Chain-of-custody is maintained between the sample collection and the laboratory receiving area if required by the client. Custody is transferred at the laboratory receiving (sample receiving) area to the laboratory internal custody. Internal custody refers to maintaining custody and tracking as the sample is subsampled and dispersed to various groups within the laboratory for analysis. Internal sample custody is maintained until disposal of the sample from the laboratory.

\subsection{Sample Receiving Procedure}

Sample receiving for PCS is generally performed by the 222-S Laboratory sample custodian. However, non-radiological samples may be received by PCS for analysis outside of the 222-S facility. When this occurs PCS will sign and maintain custody of the sample until it is returned to the customer or disposed of. The sample will be stored in the 222-SA laboratory in most cases and the chain-of-custody will be posted in the laboratory notebook.

The laboratory sample custodian shall perform the following actions at sample receiving when the customer requires chain-of-custody documentation:

- Document the carrier that delivers samples to the laboratory. A copy of the shipping document shall become part of the permanent laboratory record.

- Check that the outermost sample container(s) is not damaged.

- Check that the outermost sample seal(s) is intact.

- Verify that the chain-of-custody documentation is accurate, complete, legible, and includes the following information:

- Project name or number

- Client name and client sample number

- Date and time of sampling and sampling location for each sample

- Container types, sizes, and number of containers 
- Sample preservation (when used)

- Analyses requested (or referred)

- Signature of the person receiving and relinquishing

- Date and time of relinquishment and receipt

- Descriptions of any deficiencies identified by previous custodians.

- Verify that client sample numbers on the chain-of-custody match those on the sample containers.

- Verify that collection date and date of laboratory receipt are within method- or project-specific holding time requirements.

- Notify laboratory staff as soon as possible when the sample holding time is less than 48 hours or sample refrigeration is required.

- Notify the client of sample receipt within 24 hours, by telephone, facsimile, or electronic mail. Notification documentation (e.g., copies of the telephone logs, facsimile, or electronic mail) shall be included in the report package if requested.

- Notify the client of nonconformance within 24 hours, by telephone, facsimile, or electronic mail. Nonconformance notification and client responses shall be documented by project coordinator and kept on file in the laboratory.

In the event that prompt client response (within two business days) is not received to a notification of nonconformance, the laboratory can proceed at its discretion to anaiyze the samples. All actions and decisions must be documented in the project file, and include a summary of the nonconformances and their actions in the case narrative accompanying the final report.

When sample receipt is completed, samples are then accepted for analysis. Upon acceptance of samples, the sample custodian shall sign the chain-of-custody and shall initiate internal chain-of-custody for analytical activities.

When the samples are received by the 222-S Laboratory sample custodian (not received by the PCS personnel), the above information is available from the 222-S Laboratory sample custodian. Therefore, PCS personnel are not required to perform sample receiving procedures and only are required to follow the sample log-in and -out procedure (see Section 6.4) for those samples. 


\subsection{Sample Log-In and Tracking}

Internal chain-of-custody is initiated by sample log-in (see LO-090-101) and remains unbroken until sample disposal is completed. The sample custodian(s) is responsible for maintaining custody of the samples during the initial log-in and distribution processes. The sample custodian is responsible for ensuring that all records documenting that possession are properly completed and placed in the laboratory record system. However, the principal investigator from the PCS is responsible for notification of the sample status to the 222-S Laboratory sample custodian after completion of the test plan requirements.

The following activities are part of the sample log-in and tracking procedures:

- The samples are secured in refrigerated storage or storage cabinets as appropriate after sample log-in. Any safety hazards communicated by the client are identified.

- Sample numbers are generated by the responsible project staff and recorded in the notebook. Each sample is given a unique identifier regardless of its status. Every sample, sample replicate, and subsample shall be labeled in a manner that allows traceability to the parent sample.

- A cross-reference system is established to correlate the client sample number and the laboratory sample number using the chain-of-custody form or the project notebook.

- Sample turnover times (from the time the laboratory received samples to delivery of the data report to client) should be noted in the project notebook.

\subsection{Laboratory Internal Chain-of-Custody}

Procedure LO-090-101 addresses sample receiving and custodianship for the 222-S Laboratory and for PCS sample custodians. The internal chain-of-custody remains unbroken using a sample log-in and log-out system. Once samples are in the laboratory, sample custody is controlled by the sample custodian. The location of all samples and the person in control of the samples is traceable from the time samples are received at the laboratory until the analysis is completed and the sample is disposed of or returned to the client.

Samples that have been analyzed or stored in the facility are under the 222-S Laboratory custody (e.g., TWRS samples). These samples could be used for tests by PCS scientists. Under these situations, samples that are under the custody of 222-S Laboratory shall be logged-out and -in according to the LO-090-101-USQ procedure. However, traceability of these samples to the origin of the parent samples shall be well documented in the project notebook (which should include a copy of the chain-of-custody of the origin of the samples). It is not necessary to generate a second set of chain-of-custody documents. In addition, a notification shall be made to the 222-S Laboratory custodian for the status of these samples after completion of the task in order to complete the full cycle of the chain-ofcustody. The samples could be in one of the following three conditions: (1) the samples are 
completely used for the test; (2) samples are returned to the 222-S Laboratory after the completion of the test; (3) samples are disposed of. When samples are received by PCS outside of the 222-S laboratory, sample custody and tracking will be performed by the responsible scientist when the customer requests chain-of-custody tracking.

\subsection{Subsampling and Generating a Chain-of-Custody}

The PCS personnel also perform sample preparation and subsampling. For example, samples are broken down to subsampies by PCS personnel and shipped to other laboratories for analyses. A secondary chain-of-custody shall be generated in these cases in order to maintain unbroken custody.

The secondary chain-of-custody shall include the following information when applicable:

- Complete information regarding the origin of the samples

- All information listed in Section 6.2

- Traceability of sample identification number from the subsamples to the parent samples (this may include copies of the process notebook pages pertaining to the sample of interest).

- The information provided should be accurate and a tamper resistant seal shall be applied to the sample prior to shipment. In addition, all transportation requirements must be followed and approved by the facility shipper.

\subsection{Documentation When Chain-of-Custody is Not Required}

In some cases, such as qualitative analysis samples, the customer may not require a chain-of-custody to track samples through the laboratory. When a chain-of-custody is not required, samples will be tracked through processing notes in the laboratory notebook and these records will be maintained by the cognizant scientist or a designee until the samples are disposed of or returned to the customer. 


\section{WHC-SD-CP-QAPP-018 Rev. 0}

\subsection{Sample Disposal}

Sample disposal includes disposing of or returning the original samples to the client or to the 222-S Laboratory. The hazardous waste organization is responsible for disposing of samples that have been relinquished from the laboratory. The laboratory has procedures in place to meet the following requirements:

- Disposing of or returning samples to the client

- Maintaining records that identify the date of disposal

- Meeting all local, state, and Federal regulations

- Documenting the status of the sample in the chain-of-custody record (if samples are returned to the client, custody records shall document the return)

- Shipping documentation shall be maintained with the sample chain-of-custody by the sample custodian and shall meet Department of Transportation and applicable carrier requirements for transportation. 
WHC-SD-CP-QAPP-018 Rev. 0

\subsection{CALIBRATION}

This section describes the calibration practices used by PCS. These practices include the following:

- Calibration of laboratory measurement systems

- Traceability and documentation of standards used in calibration

- Recordkeeping for calibration data

- Calibration of balances, thermometers, and pipettes.

The initial and continuing verification of laboratory measurement system calibration is described in Section 11.

\subsection{Calibration Of Laboratory Measurement Systems (LMS)}

The requirements for calibration of each LMS are described in the laboratory technical procedure(s) that govern its operation. These requirements include, at a minimum:

- Number and range of concentrations or activities to be used in the calibration

- Frequency of calibration

- Criteria used to accept calibration

- Actions to be taken if calibration fails acceptance criteria.

Any variances from the requirements included in the laboratory procedures must be based on an agreement between the Laboratory and the client (e.g., via letter of instruction, tank characterization plan, statement-of-work).

Instruments that fail acceptance criteria shall be investigated and recalibrated. Instruments are not allowed to be used for sample analysis until they meet acceptance criteria unless the instruments are in development. When instruments and methods are being developed, data may be required for comparison with other techniques and alternative quality methods may be acceptable at the discretion of a cognizant scientist.

\subsection{Specifications Of Standards Used In Calibration}

When standards are not obtained from the 222-S Standards Laboratory, PCS is responsible for the procurement and preparation of materials used for LMS calibration. When appropriate, these materials shall be traceable to a nationally or internationally 
recognized standard agency source (e.g., National Institute of Standards and Technology [NIST]) or measurement system. Alternatively, the Standards Laboratory will procure materials of known quality and will document the materiais as described below.

The PCS Laboratory maintains records of procured reference materials that include, at a minimum:

- Source vendor

- Lot number

- Purity

- Date of preparation and/or expiration when applicable

- Certified concentration or activity of the standard material (including uncertainty if available).

Standard makeup should be described in detail in a controlled laboratory notebook. For calibration standards prepared by PCS, the following information, at a minimum, is maintained and if possible placed on the label:

- Name of the preparer

- Date prepared

- Unique identification of the standard

- Dilution or other preparation performed (e.g., digestion or mounting)

- Final concentration or activity

- Expiration date or shelf life when applicable.

When these records are maintained, the final standard shall be considered traceable to the original standard reference material.

\subsection{Thermometer and Balances}

\subsubsection{Balances}

Balances are kept on the laboratory-wide calibration program. A sticker is affixed to each balance that gives the date of last calibration and the date when the next calibration is due. Check-weights are used each day that a balance is in use to verify that the balance is still working properly. Check-weight measurements are recorded in the laboratory notebook 
being used for the testing in progress. The check-weights (two) are chosen to be within the upper and lower bounds of items being weighed that day.

\subsubsection{Thermometers}

Thermometers include liquid-in-glass and resistance thermometers. It is the responsibility of the chemist-in-charge to ensure that the accuracy of the thermometer is matched to the accuracy requirement for the test. When accurate temperature measurement is critical to the success of a test, thermometers are used that have been calibrated against a NIST standard.

\subsubsection{Calibration Records}

The PCS Laboratory maintains calibration records for all methods requiring LMS calibration. These records inciude raw data, the standard used, corresponding concentration or activity data, calculated calibration factors (e.g., regression results), criteria used to accept or reject the calibration (e.g., correlation coefficient), effective date of the calibration, and analyst's name or initials.

Calibration records are maintained in logbooks, notebooks, or electronic files as appropriate. When completed, these books are maintained in accordance with Section 10.0.

Results for testing performed at the PCS Laboratory shall include an analysis date. This date and the recorded effective calibration date permit traceability of the testing to the most recent preceding LMS calibration. If ambiguity is possible because a calibration was performed after a sample analyses on the same date, either time-of-day information must also be recorded (for both calibration and analyses), or the date of the applicable calibration must accompany analysis results. 


\subsection{LABORATORY PROCEDURES}

Activities performed by the PCS Laboratory are directed and controlled by approved procedures. Each has a unique identification code based on an approved numbering system (WHC-CM-5-4, Section 3.9).

Each procedure code includes a two or three letter identifier that denotes the general task category; e.g., LA represents analytical procedure, LC for computer procedure, LO for operating procedure, LQ for quality control, LT for laboratory technology, LR for laboratory reference material, and LAP for laboratory administrative procedure.

\subsection{Procedures and Supporting Documents}

A standard format is used for each procedure as guided by the Writer's Guide for Technical Procedures, DOE-STD-1029-92 and in WHC-CM-5-4, Section 3.9.

Test procedures for each activity are included in project-specific test plans. These procedures are prepared by chemists or other technically qualified personnel who have reviewed the process test specifications.

These procedures are reviewed by peer chemists within PCS or by the customer. All review comments are then incorporated in the final plans and procedures before they are distributed. These procedures are reviewed and administered through document control within the 222-S laboratory. The procedures are approved before use in accordance with the WHC-CM-3-5 manual, Sections 4.0 and 12.7 .

Laboratory Technology (LT) procedures are written by PCS. Approved procedures are issued as a performance "goldenrod" copy with an identification code (document number, revision/modification number), release date, official release stamp, author, author's manager, and the title. Up-to-date procedure distribution is done by Procedures Administration.

When procedures and tests are under development, desk instructions are provided and posted in a controlled project notebook. All procedures described in these instructions should be performed under the direction of the author.

A procedure can be inactivated or voided by the responsible scientist or engineer, using the Procedure Review and Approval Form (PRAF) or other signed notification with management approval.

\subsubsection{Preparation and Review of Supporting Documents}

Supporting documents (SDs) are used to document Quality Assurance Program Plans (QAPPs), Quality Assurance Project Plans (QAPjPs), basic laboratory practices, technical project plans, and laboratory test plans. Laboratory SDs do not have a specific format. 
These documents provide a combination of administrative guidance, technical direction, and quality requirements. They are reviewed internally and externally based on the topic and application. The Supporting Document Release Station assigns identification numbers for all SDs.

The responsible manager (approval authority) for each SD identifies the reviewers within WHC organizations. The approval of the SD is documented on the Engineering Data Transmittal (EDT) form (BD-7400-127) by the reviewers.

An SD can be canceled and recalled by use of an internal letter.

\subsection{Change Control}

\subsubsection{Supporting Document Changes}

An SD can be revised by the author using an Engineering Change Notice (ECN). There are two types of ECN changes: direct or supplemental changes. For direct changes, the ECN summarizes the change description and is the authorization for a new revision of the document to be issued. For supplemental changes, the ECN delineates the change details and becomes a part of the current document. Supplemental ECNs are incorporated into the document in the next revision. Both methods are detailed in Procedure EP 2.2 in WHC-CM-6-1. Approval signatures are obtained from the author and the author's manager. Document Control Service (DCS) release stamps the ECN/document, and Information Resource Management Document Control distributes the complete document revisions or documents with a supplemental ECN incorporated to the same (or officially revised) recipients as the original document.

\subsubsection{Procedural Changes}

Laboratory personnel make changes to procedures (both regulatory and internally developed procedures) for a variety of reasons. The Procedure Change Authorization (PCA) (form A-6400-242) or PRAF is used for documenting and issuing procedural changes described below. Three categories of changes are used based on the HASQAP concept.

\subsubsection{Definition Of Procedural Changes}

Substitution is an adjustment in a procedure or test that has no significant effect on final results. This would be clearly evident in the quality control data associated with the final results.

Deviation is a divergence from the original procedure that does not adversely impact the analyst's ability to meet the precision, accuracy, detection limit, selectivity, and quality control criteria of the procedure. Therefore, the decision to deviate shall be based on published literature (e.g., alternate methods), known sample chemistry or alternative testing methods that are known to show little impact on the sample. 
Modification changes the character of a method, and thereby, potentially limits a method's capability to meet the originally stated precision, accuracy, detection limit, selectivity, representativeness and quality control criteria. Because the impact of such a modification cannot be ascertained before implementation, it must be demonstrated by application. For documentation requirements, see Section 8.2.2.2.

\subsubsection{Control Of Procedural Change}

Because substitution does not impact the method performed, no documentation of change is required. Only the documentation necessary to allow reproducibility of results is required.

When a deviation is performed, the changes must be in either a desk instruction, test plan, revision, or letter of instruction. These changes must be posted in the controlled laboratory notebook along with other project notes. Documentation of deviations made shall be included in the final report narrative. Justification of the deviation should be evident in the acceptable performance associated with the final results and should also be addressed. Acceptable performance shall be demonstrated by the analyst's ability to meet or exceed the original method's precision, accuracy, detection limit, selectivity, or test criteria.

\subsection{New Analytical and Process Methods}

New analytical and process method procedures shall be qualified before use (see Section 8.4). New methods are defined as methods used for the first time whether based on published, well-understood procedures or methods, or processes and methods developed in the laboratory. The following protocol is followed as applicable for developing new methods. The first stage is to conduct and document the performance using simple standard and representative materials and to establish the following parameters as appropriate:

- Accuracy/precision

- Detection limits

- Individual interference studies

- Parameter variable studies

- Linear ranges

- Effect of interferences (chemical)

- Effect of reagent concentrations

- Effect of instrument parameters

- Kinetic effects.

- Representativeness to original feed materials and process parameters.

Performance shall be verified using the following parameters as appropriate:

- Simulants based on process knowledge

- Complex standards, if availabie or prepared simulated

- Matrix standards, if reasonable 
- Spikes or method standard addition on actual samples

- Independent analytical methods

- Sample exchange programs with other laboratories

- Comparison with standards or accepted methods on actual samples

- Comparison with data on samples that has been obtained throughout the process

- Comparison to process knowledge.

\subsection{Qualification Of Analytical Methods}

Qualification is the process of determining the suitability of a measurement system (preparative or analytical) for providing useful analytical data. Performance parameters of the method are compared with the requirements for the analytical data. Several approaches may be used to qualify a method and include the following.

- When suitable reference materials are available to adequately test method performance versus matrix effect, performance is demonstrated quite easily. This test consists of analyzing a sufficient number of reference samples and comparing the results obtained to that quoted for the particular material. A simulated matrix usually is the closest performance indicator available.

- When suitable reference materials are not available, two other approaches are considered reasonable. The first involves comparing the new method against a known, well-established (laboratory-approved or regulator-recognized) method; the second involves inter-laboratory comparisons. In limited cases, matrix spikes and/or surrogates may be used; this is the least desirable because of the limitations associated with preparing spike and/or surrogate materials. Also, spikes and/or surrogates may behave differently than the actual sample in the process investigated.

Generally accepted standards dictate using a minimum of four replicates for each test case. Whenever possible, seven replicates should be used. This data should then be used to establish statistical control on an advisory basis until sufficient data are acquired, typically considered to be 30 data sets.

A method must also be evaluated for its overall effectiveness in the areas of sensitivity, linear range limitations, matrix or analytical precision, accuracy, and counting statistics (radiochemistry), as applicable to the method and/or analyte. Method testing includes the following:

- Method detection level determination and/or minimum detectable activity (according to Section 12.0)

- Method blank evaluation

- Precision and accuracy determination

- Counter performance, if applicable

- Uncertainty 
- Determination of method interferences as appropriate to the method (i.e., preparative versus determinative).

These studies shall be documented in the procedure or in the referenced document.

\subsection{Test Plans and Desk Instructions}

Among other tasks, the PCS performs nonroutine operations in the laboratory which may be described as:

- process testing

- process development

- analytical methods development

- physical analytical measurements

- nonroutine sample preparation.

Though these tasks contain certain aspects of routine laboratory operations (such as sampie storage, radiation work procedures, sample logging), the overall tasks are not defined by routine laboratory analytical procedures (LAs) or laboratory operating procedures (LOs).

Instead, work is conducted following test plans or desk instructions written by the cognizant scientist; reviewed, if applicable, by the technicians who may perform the work; and approved by the PCS manager. The test plans may require review and approval by relevant safety, quality assurance, program, and other cognizant engineers and scientists associated with the testing program. Copies of the applicable test plans and desk instructions are kept by the PCS manager.

The scientist and technicians of PCS shall ensure that work is performed safely and expeditiously within the goals of the test plan or desk instructions. The scientist and technician shall jointly review and "walk through" these test plans, if possible. The laboratory test plan or desk instructions should pay special attention to the following:

- safety issues

- waste handling and disposal

- data logging

- equipment operation.

This joint review shall constitute on-the-job training for the laboratory test plan or desk instructions. 


\subsection{DATA COLLECTION, REDUCTION, AND REPORTING}

Data collecting and reporting processes include proper sampling (client's responsibility); documenting sample splitting, preparation, and associated observations; documenting chain-of-custody; collecting raw data; data reduction and calculations; and transferring results to a final form for reporting.

\subsection{Data Collection}

Raw data are generated by either manual or electronic means in PCS. Manuai collection is done by the analyst and recorded on logbook/notebooks according to applicable test plans. Raw data is defined as data that can not be easily derived or recalculated from other information. Raw data is collected and maintained based on the method or instrument. For instruments that have a built-in integration or detector signal processing software, the instrument controller output is considered the raw data.

Information used in sample preparation (e.g., weight or volume of sample used, percent dry weight for solids, dilution factor used) and in the calculations (e.g., raw data or detector signal data, calibration, interference check results or correction factors, blank or background correction values) shall be maintained, if available, in order to enable reconstruction of the final results at a later date. In most cases all processing information is available in the PCS project/laboratory notebook.

The cognizant chemist is responsible for recording or maintaining raw data in the logbook/or notebook. To guard against loss, logbooks/notebooks shall be stored in the approved locations when not in use. Approved locations are documented by a letter issued from the PCS manager.

Each individual generating data or information is responsible for identifying data entry errors, sample identification errors, and calculation errors. The person entering the raw data is responsible for checking the integrity between raw data and entered data. All these entries must be legible, understandable, and reproducible with a standard photocopier. In addition, if the raw data are used in calculations that are pertinent to a report, the calculations shall be reviewed by a peer scientist. Any corrections found will then be entered by the peer as described below.

Data entry errors shall be corrected by one line drawn through the error that is then dated and initialed. Data changes shall be marked by one line drawn through the change that is then dated, initialed, and explained, as appropriate.

Data records are dispositioned according to the laboratory Record Inventory and Disposal System (RIDS) (See Section 10.0). 


\subsection{Data Reduction}

Data from sample analysis should be reduced according to applicable procedures, desk instructions, and test plans. Data reduction includes activities that convert analytical measurements and instrument responses into reportable results. These activities may involve calculations, changes to the units or the data values, statistical and mathematical analysis, as well as correction of final results for appropriate backgrounds and/or interference (e.g., Compton effects for gamma energy analysis [GEA] and inter-element correction for inductively coupled plasma spectrophotometry [ICP]). Data reduction shall be documented.

Calculations that are used for generating a final result are described in the test plan or notebook instructions found in the laboratory or project notebook. The calculations are peer reviewed.

Computer programs and spreadsheets used for data reduction shall be verified with known results before use to ensure calculation and data manipulation programs perform properly. All spreadsheets are peer reviewed and example calculations are included as appendices to final reports.

\subsubsection{Significant Figures}

Data reduction procedures on significant numbers, rules for rounding, and reporting rules are provided in LO-150-127. Vendor-supplied software may not meet the general rules for significant figures; the laboratory should work with the client to determine the best way to report results, based on project needs.

Once the number of significant figures obtainable from a type of analysis is established, data resulting from such analyses are reduced according to set rules for rounding off (see Section 9.2.2).

Reported values should contain only significant figures and the exponential notation should be used.

\subsubsection{Rounding-Off Methods}

The rounding-off method is used when an observed or calculated value needs to be reported in a limited number of significant figures for determining conformance with specifications. Numbers shall be rounded at the end of a series of calculations to eliminate rounding error (see LO-150-127).

\subsection{Data Review}

Data review refers to the process of determining whether data conform to specified requirements. Analytical data are reviewed prior to posting on LABCORE or reporting to PCS. The review system is described below and is in accordance with laboratory-established 
procedures to review data before data reports are prepared. These guidelines are followed by PCS when performing analytical measurements that are reported to the customer.

The technologists and/or chemists can perform data entry and calculate results and/or QC parameters (precision or accuracy). These calculated results or data are reviewed by the chemists. The data review activities are briefly described below.

- The person who is responsible for calculating data shall check calculations against desk instructions, procedures, or test plans.

- The chemist is responsible for checking the calculations, checking calibration information to ensure the stability and accuracy of the instrument, and checking administrative records or documents to ensure the calculated results are associated with the appropriate samples and final reports.

- The chemist/scientist is responsible for reviewing data against applicable (QC) criteria to verify that the test is performing acceptably, against the available historical instrumental values or process knowledge data (see Section 11.0 for details). If QC criteria does not meet $\mathrm{QC}$ requirements, data within the batch shall be evaluated to determine if there were any adverse effects on the data; the sample shall be rerun or the data shall be reported with narrative(s).

- Sample identification during sample collection and preparation, and certain raw data records are transferred manually and are checked by the analyst, chemist, and/or by the manager.

\subsection{Data Reporting}

Measured parameters, the details of analysis, and the data values are reported in accordance with the requirements of the end-user as specified in the agreement between the laboratory and the client. The type of information, level of approval, data reporting format, and means of delivery shall be discussed and agreed upon between the laboratory and the client (see Section 9.4.1 for information required in the reporting documentation).

The PCS Laboratory reports are in the form of a letter or a supporting document report. Technical reports or letters require peer or management review and the reviewer's initial before they are distributed to the client.

\subsubsection{Data Reporting Documentation}

The reporting documentation shall include the following information:

- Laboratory name and address 
- Sampie information including unique laboratory identifier cross-referenced to client identification, sample collection date and time, date of sample receipt, and date(s) of sample preparation and analysis

- Analytical units and results, reported with an appropriate number of significant figures

- Detection limits (where applicable)

- Method reference

- Identification of any amended test results; signature and title of person accepting responsibility for the report contents; and identification of subcontracted resuits if applicable

- Appropriate QC results (correlation with sample batch shall be traceable and documented)

- Additional data reporting (e.g., the percent of moisture/solid or correction for equivalent dry weight may be included if requested by the client).

\subsubsection{Preliminary Reporting}

If necessary, a preliminary data reporting system may be established between the client and the laboratory to address emergency situations. The type of information, level of approval, data reporting format, and means of delivery should be discussed and agreed upon between the laboratory and the client before the project starts. The emergency situation may include, but is not limited to, screening activities for safety issues, critical analytes, or limiting sample amount. 


\subsection{RECORDS AND DOCUMENTS}

The PCS group implements a system for preparing, reviewing, approving, issuing, using, and revising documents that prescribe or report work processes, test results, and analyses. In addition, PCS has established a system of identifying, preparing, approving, transmitting, correcting, distributing, retaining, and disposing of quality records that is administered by the PCS manager.

The quality records include, but are not limited to the following:

- Procurement documents

- Training records

- Calibration records

- Maintenance records

- Chain-of-custody forms

- Supporting documents

- Internal letter reports.

Records are tracked through reviewed controlled laboratory notebooks or files maintained by PCS management. In addition, IRM is responsible for the quality records and document system. Specifications, preparation, review, approval, and maintenance of quality records are governed by the WHC-CM-3-5, Sections 5 and 9. A computer system is used to maintain and access quality records including electronic media to ensure the records are useable and retrievable.

\subsection{Generation of Quality Records}

Documents and data referenced by final reports shall be retrievable from the records system, except for readily available references (e.g., national codes and standards). In addition, all final reports will cross-reference the laboratory notebooks in which data is recorded.

\subsection{Receipt Control}

The Program Management and Integration organization is responsible for maintaining the Laboratory Technical Information Center and for coordinating retrieval of the record copy that is maintained in the laboratory. The IRM is responsible for receiving the records and implementing a system of receipt control of the records for permanent and temporary storage. Information Resource Management has the capability to do the following:

- Designate the required records

- Identify records received

- Receive and inspect incoming records

- Submit completed records to the records-holding facility without unnecessary delay. 


\subsection{Records Validation}

Records considered valid shall be signed, initialed, stamped, or otherwise authenticated, and dated by the document's originator (WHC-CM-3-5, Sections 9 and 4). Electronic records shall be validated by signing and dating a paper copy of the first page of the record. These records may be originals or copies. Handwritten signatures are not required if the record is clearly traceable to the person or organization who created the record.

\subsection{Correcting Records}

Correction to the quality records system is described in WHC-CM-3-5, Section 9, 5.4. The correction of technical or quality-related information shall have an appropriate review and approval by an authorized person of the originating organization that was responsible for the approval of the in-process document. The name of the person authorized to issue the correction and the date of correction shall be marked on the quality record.

\subsection{Records Identification and Indexing}

Records are cataloged and tracked on a database and can be retrieved through a variety of topics including project or activity identification. Record retention times are controlled by the RIDS system. Location of the record is indexed on the Record Holding Area Management Information System (RHA-MIS).

\subsection{Maintenance and Retention of Records}

Controlled manual WHC-CM-3-5, Sections 5 and 9 describes the maintenance of active records for transmittal, distribution, retention, protection, preservation, traceability, accountability, disposition, and retrievability.

Section 9 describes the criteria for lifetime records and nonpermanent records. The appropriate quality record retention time is monitored by the RIDS system. Expired records are destroyed after reaching the scheduled retention time.

\subsubsection{Access Control}

Access to the quality records system is limited to only authorized personnel (WHCCM-3-5, Section 5). 


\section{WHC-SD-CP-QAPP-018 Rev. 0}

10.6.2 Replacement, Restoration, or Substitution of Records

Lost or damaged records shall be replaced, restored, or substituted when applicable (WHC-CM-3-5, Section 9).

\subsubsection{Records Turnover to Client}

Records turned over to the client are copies of the original records. Original records are kept at PCS and controlled according to the appropriate record requirements defined in WHC-CM-3-5. 


\subsection{QUALITY CONTROL}

This section describes the quality control (QC) measures used for laboratory testing performed by PCS. The degree of QC required for testing is determined through negotiations with the client, based on the end-use of the data. The negotiations are documented in a test plan before the work is initiated.

\subsection{Materials}

Materials for testing inciude chemicals, glassware, balances, pipets, thermometers, and other physical items needed for performing the tests. It is the responsibility of the chemist or engineer in charge of a project to ensure that the materials are appropriate for the use to which they are put. (The term chemist is used henceforth to mean the chemist or engineer in charge of the testing.)

\subsubsection{Chemicals}

Chemicals are reagent grade or better whenever possible. Certain chemicals are not available commercially in reagent grade. If it is important to know the exact composition of a technical grade chemical, it is analyzed before it is used for the test.

\subsubsection{Reagents}

Reagents (defined here as combinations of chemicals, or a solution of a chemical dissolved in water or some other solvent) can be prepared as part of the test, or can be procured through the Analytical Services Standards Laboratory. The accuracy with which the composition of a reagent needs to be known is determined by the chemist in charge of the test. Reagents are labeled with expiration dates. If an expiration date is passed, the reagent must be either recertified before it can be used, or it must be discarded as waste.

\subsubsection{Glassware}

Volumetric glassware includes graduated cylinders, graduated centrifuge cones, volumetric flasks, glass to-deliver (TD) and to-contain (TC) pipets, burets, syringes, pycnometers, and others. It is the responsibility of the chemist-in-charge to know the inherent accuracy of each measuring device used and to fit the accuracy of the device to the accuracy needed for the test. It is also the responsibility of the chemist-in-charge to determine when (if) the device requires calibration in order to meet the accuracy requirement.

\subsection{Design}

All laboratory testing requires test plan approval before testing is initiated. The format for the test plan is dependent upon the level of effort that the test will require. Test plan requirements are documented in WHC-CM-5-4, Section 5.4. 
The chemist and client determine through discussions what data is needed by the client. The chemist writes a test plan to describe how the testing will be performed in order to provide the required data. The test plan is then reviewed and approved by the chemist, the chemist's manager, and (if required) the client.

The chemist may consider a variety of inputs to design a test plan. Historical or reference data should always be considered. The chemist should also be aware of any process knowledge or process flowsheets associated with the system being tested. The feasibility of applying a variety of quality control checks (see Section 11.3) should also be considered so that the data needed for the checks can be obtained. Statisticians may be consulted, where appropriate or where multiple experiments are needed, to provide input on a statistical design of the experimentation. (The statisticians are also sometimes consulted on the interpretation of the data at the conclusion of the test.)

\subsection{Quality Control Checks}

A variety of quality control checks can be made on the data acquired in a carefully controlled experiment. The nature of these quality control checks varies from one type of test to another, so some examples may serve to indicate the variety of checks that can be applied.

\subsubsection{Mass Balance/Charge Balance}

Samples are often analyzed for virtually all of the constituents that are believed to be present in the sample. If the concentrations of all the constituents are expressed in weight percent, their sum should equal $100 \%$ (mass balance). A sum greater than $100 \%$ would indicate an analytical error. A sum less than $100 \%$ could mean an analytical error, or a component has not been analyzed. Care must be taken by the chemist that each analyte is assigned to the correct species in the sample. For example, an analytical result for total inorganic carbon (TIC) would have to be multiplied by the factor $(60 / 12)$ if the TIC is present in the sample as carbonate ion $\left(\mathrm{CO}_{3}^{-2}\right)$.

The calculation of charge balance can be applied under similar circumstances (i.e., if all ionic components are included in the list of analytes). The concentration of each ionic component is expressed in terms of equivalents per liter (or per gram). The total equivalents of cations should equal the total equivalents of anions. The balance is usually expressed as a ratio (total cation equivalents/total anion equivalents), which should equal 1:00. A ratio higher than 1 would indicate that one or more cations are overstated, or that one or more anions are understated. Again, it is important that the analyte is assigned to the species actually present in the sample when performing this calculation.

The mass and charge balance together often show the key to an error in the analyses. For example, the combination of a high mass balance $(>100 \%)$ and a low charge balance $(<1.00)$ would point to erroneously high anionic components. Knowledge of the chemistry of the system may allow the chemist to determine which single component's concentration 
(or which group of components) is too high. If the mass balance is good (97\% to $103 \%$ is normally considered very good in process chemistry work) and the charge balance is good (0.97 to 1.03 ), then the chemist and client can have confidence that there is no gross error in the concentrations of any of the major components.

\subsubsection{Relationship of Samples in a Set}

Chemists often take advantage of relationships among samples in a set of samples to search for anomalous results. Testing may involve measuring the response of a system property (e.g., solubility, hydroxide concentration, distribution coefficient) to a change in a system parameter (e.g., temperature, $\mathrm{pH}$, ionic strength). It will usually be the case that a graph of the system property versus the system parameter can be described by some sort of regression line. An erroneous system property measurement would be observed as a flier, or a point that deviates significantly from the regression line.

Mass balance takes on another context in separation process experiments, where the total amount of a given component present in a sample before a test must be equal to the total amount of the same component present in the system (perhaps several samples) after the test. For example, where distribution coefficients are measured for a solvent extraction process, the amount of component present in the feed sample must be equal to the sum of the amounts present in the organic and aqueous phases after extraction.

Another type of relationship, a dilution relationship, exists between the liquid phase of a sludge sample and the water-wash liquid after the solids in the sample have been washed with water. This is a common sample pair encountered in characterization of sludge samples. For all of the components that exist oniy in the liquid phase of the sample (i.e., the sludge is not saturated in those components), there should be a constant ratio of the concentration in the liquid phase to the concentration in the water wash. Normally, there are several such components, and it is easy to establish an average ratio of concentrations.

Components would have a ratio significantly lower than the average if they were present in the solid phase in the original sample, and dissolved in the water wash. This is often the case with components like nitrate and carbonate. Components would have a ratio significantly higher than the average only if they were more soluble in the original liquid phase than in the water wash. This rarely happens in the case of aluminum, whose solubility can be lowered when it transitions from aluminate ion to aluminum hydroxide when the $\mathrm{pH}$ is lowered.

To some extent, the availability of quality control checks based on sample relationships is determined by the ingenuity of the chemist to look for the relationships.

\subsubsection{Blanks, Duplicates, Spikes}

Field blanks, procedure/reagent blanks, duplicate anaiysis of samples, and analysis of spiked samples are all quality control checks on the analytical laboratory that should be negotiated and included in the test plan. In some cases, it may be sufficient to indicate the protocol under which the samples should be analyzed. 
The analysis of blind duplicate samples is not part of the normal QC requirements imposed by the laboratory. Blind duplicate samples may or may not be prepared and submitted for analysis by the chemist in charge of the testing. When they are used, they provide a good indication of the analytical error associated with the tests. For that reason, they are normally used with statistically designed experiments.

\subsection{Peer Review}

At the conclusion of the testing and analysis, a report is prepared by the chemist. The report may be an internal memo or a supporting document and the report is reviewed by either the chemist's manager or another chemist who is familiar with the test program. (This peer review is the minimum amount of review required. There may be other levels of review required.) 


\subsection{PROCEDURES TO ASSESS DATA QUALITY}

This section provides various formulas that are typically used to compute quality assurance parameters that are used to assess data quality in the results. The overall data integrity will be assessed against the project (e.g., check mass/charge balance).

\subsection{Precision}

Precision has been defined in Section 4.2.1. Precision for the sample is estimated by using duplicate and/or replicate, or matrix-spike suplidates. Samples used to calculate precision should contain the concentrations of analytes above the method detection limit (MDL). The precision of test results is expressed as the relative standard deviation (RSD) or the relative percent difference (RPD). The precision of a method in a given matrix is expressed as the RSD or the RPD among matrix spike duplicates.

\subsubsection{Relative Standard Deviation}

The RSD is used when at least three replicate measurements are performed on a given technique. The RSD is computed using the following equation:

$$
\mathrm{RSD}=\frac{\mathrm{s}}{\overline{\mathrm{x}}} \cdot 100
$$

where

$\mathbf{s}=$ Standard deviation with $\mathbf{n}-1$ degrees of freedom

$\mathrm{n}=$ Total number of observed values

$\overrightarrow{\mathrm{x}}=$ Mean of all observed values.

\subsubsection{Relative Percent Difference}

The RPD is used when two measurements exist. The RPD is generally used to express the precision of matrix duplicate or matrix spike duplicate samples. The RPD is computed using the following equation:

$$
R P D=\frac{\left|x_{1}-x_{2}\right|}{\bar{x}} * 100
$$

where

$$
\begin{aligned}
x_{1,2} & =\text { Observed values } \\
\overline{\mathrm{x}} & =\text { Mean of observed values }
\end{aligned}
$$




\subsection{Accuracy}

\subsubsection{Method Accuracy Based on Sample Spike}

Accuracy has been defined in Section 4.2.2. Accuracy for the sample is expressed as the percent recovery (\%R) of a matrix spike (or matrix spike duplicate) sample. The percent recovery is calculated based on the following equation:

$$
\% R=\frac{(S S R-S R)}{S A} * 100
$$

where:

SSR $=$ Spiked sample result

$\mathrm{SR}=$ Sample result

$\mathrm{SA}=$ Spike added.

\subsubsection{Method Accuracy Based on Standard}

The accuracy of an analytical method is expressed as the percent recovery of a standard (\%R). The percent recovery of a standard is calculated according to the following equation:

$$
\% R=\frac{A_{n}}{A_{k}} * 100
$$

where:

$A_{m}=$ Measured value of the standard analyte

$A_{k}=$ Known value of the standard analyte

\subsection{Measures of Agreement}

\subsubsection{Percent Difference}

The percent difference (\%D) is often used to compare one reference point to another. The percent difference is calculated using the following equation:

$$
\% D=\frac{|I-C|}{I} * 100
$$

where

$I=$ Observed value used as the reference point

$\mathrm{C}=$ Compared value. 


\subsubsection{Bias}

Bias is often used to measure the deviation of a measured value from a known value or accepted reference value. Bias can be assessed by comparing a measured value to an accepted reference value in a sample of known concentration or by determining the recovery of a known amount of contaminant spiked into a sample. Thus, the bias caused by the matrix effects based on a matrix spike is calculated using the following equation:

$$
B=\left(X_{s}-X_{u}\right)-K
$$

where

$X_{s}=$ Measured value (e.g., spiked sample)

$X_{u}=$ Miscellaneous contribution (e.g., sample contribution). If no miscellaneous contributions exist, $\mathrm{X}_{\mathrm{u}}$ would be zero.

$\mathrm{K}=$ Known value (e.g., true spiked value).

\subsection{Detection Limit Considerations}

Detection limit is defined as the smallest amount that can be detected above the noise in a procedure and is within a stated confidence limit. Several types of detection limit are commonly used and are discussed in the following. The investigator is responsible to select a proper detection limit based on the following definitions for a specific method or specific set of data.

\subsubsection{Method Detection Limit}

The MDL is defined as "the minimum concentration of a substance that can be measured and reported with $99 \%$ confidence that the value is greater than zero" (SW-846, consistent with the requirements specified in 40 CFR 40 Appendix B to 40 CFR 136) and is briefly described in the following text.

The concentration of the MDL for the analyte of concern can be estimated by using one of the following:

- Instrument signal-to-noise ratio within the range of 2.5 to 5

- Region of the standard curve where there is a significant change in sensitivity (i.e., a break in the slope of the standard curve).

When determining the MDL, a minimum of three analyses are required in a matrix spiking with the analyte of interest at a concentration three to five times the estimated MDL. Whenever possible, the matrix should be similar to the sample matrix. When not possible, the matrix will be water. All sample processing steps of the analytical method shall be included in the final determination of the MDL. 
Variance $\left(\mathbf{S}^{2}\right)$ is determined from the replicate measurements, as shown:

$$
S^{2}=\frac{1}{(n-1)}\left[\sum_{i=1}^{n}\left(x_{i}-\bar{x}\right)^{2}\right]
$$

where

$\mathrm{x}_{\mathrm{i}}=$ Measurement of the variable $\mathrm{X}$

$\overline{\mathrm{X}}=$ Mean of observed variable $\mathrm{X}$.

The MDL should be determined by the following equation:

$$
\text { MDL }=\mathrm{t}(n-1, \alpha=.99) \cdot(\mathrm{s})
$$

where

$\mathrm{t}_{(\mathrm{n}-1, \alpha=.99)}=$ One-sided t-statistical value appropriate for the number of samples used to determine standard deviation

$S=$ Standard deviation obtained from the MDL replicate measurements.

\subsubsection{Instrument Detection Limit}

Instrument detection limit (IDL) is determined by spiking reagent water with each analyte of concern. The following considerations apply to the selection of the IDL standard.

- Concentration of the IDL standard should be at least equal to or in the same concentration range as the estimated IDL.

- Concentration of the IDL standard should be in the region of the standard curve where there is significant change in sensitivity.

A minimum of seven aliquots of the IDL standard are required to determine the IDL. The IDL standards are run through the analytical process only. The IDL is calculated the same as the MDL.

Ideally, each analytical method should have data supporting a MDL for the specific matrix of each sample. If this is not practical, MDL on generic matrices (e.g., deionized water, ground water, soil) can be used to estimate the sample-specific MDL. If the MDL cannot be determined, at a minimum, IDL information will be available and can be used.

\subsubsection{Estimated Quantitation Limit}

The estimated quantitation limit (EQL) has been defined by RCRA as the lowest level that can be reliably achieved within specified limits or precision and accuracy during routine laboratory operating conditions. The analyte concentration at the estimated quantitation limit 
is determined using the following guidance: (1) 5 to $10 \mathrm{X}$ MDL or IDL, or (2) the lowest non-zero standard in the calibration curve. In some cases, sample dilutions affect the quantitation limit. Then the quantitation limit is calculated as dilution factor times the EQL as defined above.

The quantitation limit can be used to qualify the sample resuits or used to compare the data quaiity requirements from the end user of the data. When results are less than the quantitation limit or detection limit, sample results should be reported with appropriate qualifier. Results that are less than the IDL or MDL are reported as the numeric limit preceded by a less than symbol. If the detection limit is reported elsewhere, the result may be reported as undetectable. Results falling between the IDL (or MDL) and the EQL can be reported with appropriate qualifiers or discussed in the case narrative. 


\subsection{AUDITS}

A quality assurance program can only be effective if systems are in place to continuously monitor or assess the laboratory's ability to conform to program requirements. The systems are a collection of QA audits and assessments that do the following:

- Measure the degree of conformance with the laboratory's QA program

- Determine the effectiveness of the QA program

- Permit continuous improvement of the quality of products or services the laboratory provides.

To achieve this goal, personnel who perform independent assessments shall be technically qualified and have sufficient authority and freedom from the line organization to carry out their responsibility. The independent assessment process shall incorporate a performance-based approach with emphasis on the results of work process and compliance to requirements.

\subsection{Management Audits}

Management audits are directed by laboratory management or their delegates. These audits shall be conducted annually, at a minimum. The assessment may identify topics from areas of particular concerns or include one of the following:

- Development of technical procedures

- Quality and applicability of current management systems (e.g., QA manual, administrative procedures)

- Effectiveness of design and conduct of audits

- Review and evaluation of performance indicators, findings or concerns from surveillances, assessments/audits, or effectiveness of corrective actions.

\subsection{Data Quality Audits}

The objective of data quaity audits is to determine if adequate information and documentation exists within a given data package to support an assessment of its quality. Furthermore, the degree of conformance to client data quality requirements shall be evaluated and documented. The PCS manager or principal investigators perform data quaiity audits. 
WHC-SD-CP-QAPP-018 Rev. 0

\subsection{External Audits}

External audits of the laboratory are performed by agencies or groups that are not under the controi of laboratory management. External audits may consist of inspections, interviews, and evaluations that focus on the laboratory's ability to meet client, program, or regulatory requirements. Laboratory management shall be responsible for initiating, tracking, following up, and documenting all corrective actions that are required as a result of external audits. 


\subsection{PREVENTIVE MAINTENANCE}

Preventive maintenance of laboratory instrumentation helps to ensure its availability for analytical measurements by reducing downtime and avoiding inconsistencies in instrument performance.

The Laboratory has an Instrument Preventive Maintenance Program. This program is described in Section 10.1 of WHC-CM-5-4.

Significant components of this program include the following: scheduling, documentation, and maintaining spare parts.

- Schedules are developed by the cognizant scientist and are based on the manufacturer's recommendations, operational experience, and usage. Typical components of schedules include periodic instrument checks (e.g., daily, weekly, or monthly), activity-based checks (e.g., analysis of instrument check standards or control chart trends), routine service requirements, and sources of service (e.g., analytical troubleshooting by the cognizant scientist, instrument troubleshooting and repairs by instrument technologists, on-call vendor service, or vendor service contracts). Most maintenance is scheduled through the laboratory Job Control System and all documents pertaining to maintenance are kept by them.

- Spare parts may be maintained, which include day-to-day consumable or other known-to-fail parts as suggested by the cognizant scientist.

- Spare parts may be formally maintained in the WHC spare parts inventory, administered at the Laboratory by the AS Laboratory Engineering group. The current status of this inventory can be queried through the General Inventory Catalogs Program (GIC), available on the Hanford Local Area Network (HLAN) through Soft Reporting.

- Spare parts may aiso be obtained through:

- Overnight parts availability from suppliers

- Availability of back-up instrumentation

- Vendor service contracts.

In the event of complete instrument failure, the 222-S Laboratory has multiple units of equivalent instruments available. Pacific Northwest National Laboratory (PNNL) has similar instrumentation in many areas. 


\subsection{CORRECTIVE ACTION AND CONTINUOUS QUALITY IMPROVEMENT}

The corrective action process consists of the identification of an adverse condition or deficiency, root cause analyses, determination of corrective action, and documentation. When fully implemented, this process is the basis for continuous improvement. The laboratory will follow guidelines from the WHC-CM-1-3 MRP 5.1, WHC-CM-4-2 QI 16.016.2, and/or WHC-CM-5-4 Chapters 6 and 8.

The external sources that may initiate corrective actions are clients (e.g., Tank Farms and Evaporator) or regulatory agencies (e.g., DOE and EPA).

The corrective action process shall ensure that laboratory personnel at all levels are responsible for initiating corrective action when conditions may adversely impact laboratory systems.

Examples of conditions where corrective action shall be implemented are included in the following:

- Engineering changes suggested by PCS to a test plan

- Documentation errors

- Failure to comply with approved procedures

- Failure to follow the preventive maintenance program

- Failures in instruments

- Noncompliance issues identified by audits, surveillances and assessments

- Failure to follow client analytical requests and/or data quality objectives (DQOs) - this condition may be addressed as part of the narrative in the report to the client.

\subsection{Evaluating Impact}

The corrective action processes listed above describe the provisions for (1) determining the significance of the problem and (2) taking effective corrective action based on the potential impact on the data quality. The process is typically initiated by submitting a fact sheet, critique, unusual occurrence report, nonconformance report, or letter of observation.

Implementation of corrective actions shall be verified as appropriate. Reports of corrective actions are included in narrative documents or in the final report. 
In order to promote timeliness and efficiency in the laboratory, corrective actions are made at the lowest management level possible.

\subsection{Recurring Conditions Adverse To Quality}

These processes are established in the procedure used to correct the problem. The measures to eliminate or minimize recurrence of quality problems shall be established using the following provisions. These determinations shall include but not be limited to the following.

- Determine the events leading to the adverse condition.

8 Understand the technical and work activities associated with the quality problem.

8 Ascertain the quality problem's generic implications.

8 Determine the extent to which similar quality problems (or precursors to the problem) have been recognized.

- Determine the effectiveness of any corrective actions that were taken.

- Determine the impacts on the completed work.

8 Recommend actions that can be taken by the responsible organization to preclude recurrence.

- Determine if stopping the work associated with the activity is necessary.

\subsection{Trend Analysis}

Calibration standards or other methods can be used to ensure accuracy of measurements. Data is examined for internal consistency (e.g., mass balance in Section 11).

\subsection{Root Cause Analysis}

When significant errors are repeated, an investigation will be conducted commensurate with the importance or significance of the problem. In addition, remedial action shall be taken to correct the problem. 


\subsection{Continuous Quality Improvement}

Quality improvement is a continuous process and is designed to reduce the variability of every process that influences the quality of the product. This concept is used throughout this quality assurance program. Laboratory activities, analytical measurements and results, and QA/QC activities are documented and are traceable for evaluation. For example, management or personnel can analyze the performance indicators, corrective actions, or assessment to identify actions as a means of continuous quality improvement. During process or analytical methods development, improvements and innovative methods should be documented in the laboratory notebook used for development notes. Later, these concepts may be useful in implementing the methods. Information obtained from lessons-learned evaluations, or peer reviews also are used for management planning and problem prevention as a means of continuous quality improvement. This information is normally passed along to workers as soon as it is realized. 
WHC-SD-CP-QAPP-018 Rev. 0

\subsection{QUALITY ASSURANCE REPORTS}

\begin{tabular}{|c|c|c|c|c|c|c|}
\hline REPORTS & AUTHOR & APPROVED & FREQUENCY & DISTRIBUTION & $\begin{array}{l}\text { CORRECTIVE } \\
\text { RESPONS- } \\
\text { IBILITY }\end{array}$ & $\begin{array}{c}\text { TYPE OF } \\
\text { DOCUMENT }\end{array}$ \\
\hline $\begin{array}{l}\text { Responses } \\
\text { Data Review }\end{array}$ & $\begin{array}{l}\text { Technical } \\
\text { Staff }\end{array}$ & $\begin{array}{l}\text { Peer Review } \\
\text { PCS Manager }\end{array}$ & Ad hoc & $\begin{array}{l}\text { Lab } \\
\text { Management }\end{array}$ & $\mathrm{N} / \mathrm{A}$ & Interna! Form \\
\hline Case Narrative & $\begin{array}{l}\text { Technical } \\
\text { Staff }\end{array}$ & PCS & $\begin{array}{l}\text { Per Project } \\
\text { Repor }\end{array}$ & Per Report & $\mathrm{N} / \mathrm{A}$ & N/A \\
\hline Case Summary & $\begin{array}{l}\text { Responsible } \\
\text { Investigator }\end{array}$ & $\begin{array}{l}\text { PCS } \\
\text { Manager }\end{array}$ & $\begin{array}{l}\text { Per Project } \\
\text { Report }\end{array}$ & Notebook & N/A & N/A \\
\hline $\begin{array}{l}\text { External } \\
\text { Audit } \\
\text { Assessment }\end{array}$ & Auditor & $\mathrm{N} / \mathrm{A}$ & Ad hoc & $\begin{array}{l}\text { Lab } \\
\text { Management }\end{array}$ & Lab & $\begin{array}{l}\text { Intemal/ } \\
\text { External } \\
\text { Letter }\end{array}$ \\
\hline $\begin{array}{l}\text { Exiema! } \\
\text { Surveillance }\end{array}$ & Auditor & N/A & Annually & $\begin{array}{l}\text { Lab } \\
\text { Management }\end{array}$ & Lab & $\begin{array}{l}\text { Interna! } \\
\text { Letter }\end{array}$ \\
\hline
\end{tabular}




\subsection{DATA VALIDATION}

Project requirements must be defined in specific authorized documents (e.g., test plan), along with the systematic process to be used in verification or validation of project data. In cases where data must be validated, a specific set of acceptance criteria must be defined that ensures that the data generated are adequate for their intended use. The PCS policy for data evaluation and validation relies heavily on peer review or independent review. An independent (other than the data generator: one-on-one relationship or peer review) will apply to the results before submitting to the client. All data interpretation is typically performed by the customer. However, in some cases, such as during analytical methods development, the customer requests interpretation and evaluation of the methods or data generated from the process. In these cases, the customer specifically requests the evaluation on the test plan or formal letter of instruction. 


\subsection{PROCUREMENT CONTROLS}

The PCS Laboratory follows the WHC-CM-2-1 (Procurement Manual and Procedures) and WHC-CM-4-2, QR 4.0 "Procurement Document Control" manual to ensure the procurement process is documented and controlled. The controls ensure procured items and/or services can do the following:

- Conform to established specifications

- Meet acceptable quality

- Perform as expected.

When there are indications that subcontractors knowingly supplied items or services of substandard quality, this information shall be forwarded to laboratory management for appropriate action (e.g., subsequent reporting to the U.S. Department of Energy Office of the Inspector General). 
WHC-SD-CP-QAPP-018 Rev. 0

\subsection{REFERENCES}

10 CFR 830.120, 1994, "Quality Assurance Requirements," Code of Federal Regulations, Title 10, Part 830.120, U.S. Environmental Protection Agency, Washington, D.C.

40 CFR 136, 1994, "Guidelines Establishing Test Procedures for the Analysis of Pollutants," Code of Federal Regulations, Title 40, U.S. Environmental Protection Agency, Washington, D.C.

DOE, 1991, Quality Assurance, DOE Order 5700.6C, U.S. Department of Energy, Washington, D.C.

DOE, 1992, Writer's Guides for Technical Procedures, DOE-STD-1029-92, U.S. Department of Energy, Washington, D.C.

EPA, 1980, Guidelines and Specifications for Preparing Quality Assurance Program Plans, EPA QAMS-004/80, U.S. Environmental Protection Agency, Washington, D.C.

EPA, 1980, Interim Guidelines and Specifications for Preparing Quality Assurance Project Plans, EPA QAMS-005/80, U.S. Environmental Protection Agency, Washington, D.C.

EPA, 1992, Test Methods for Evaluating Solid Waste: Physical/Chemical Methods, SW-846, U.S. Environmental Protection Agency, Office of Solid Waste and Emergency Response, washington, D.C.

Meznarich, H. K., 1995, 222-S Laboratory Quality Assurance Plan, WHC-SD-CP-QAPP-016, Rev. 1., Westinghouse Hanford Company, Richland, Washington.

Resource Conservation and Recovery Act of 1976, 42 USC 6901 et seq.

Rich, H. S., 1995, Configuration Management Plan for LABCORE Program, WHC-SD-WM-CM-002, Westinghouse Hanford Company, Richland, Washington.

Weaver, L. L., 1992, Laboratory Facilities Hazards Identification and Evaluation, WHC-SD-CP-HIE-001, Rev. 0-E, Westinghouse Hanford Company, Richland, Washington.

Westinghouse Hanford Company Analytical Services procedures:

LO-090-101-USQ, 222-S Laboratory Sample Receiving and Custodianship

LO-150-127, Mathematic Aspects of Checking and Reporting Results

Westinghouse Hanford Company Controlled Manuals:

WHC-CM-1-3, Management Requirements and Procedures 
WHC-CM-2-1, Procurement Manual and Procedures

WHC-CM-3-5, Document Control and Record Management Manual

WHC-CM-3-10, Software Practices

WHC-CM-4-2, Quality Assurance Manual

WHC-CM-5-4, Laboratories Administration

WHC-CM-6-1, Standard Engineering Practices

WHC, Configuration Management Plan for LABCORE Program, WHC-SD-WM-CM-002, Westinghouse Hanford Company, Richland, Washington.

WHC, LABCORE Software Test Plan, WHC-SD-WM-CSWD-058, Westinghouse Hanford Company, Richland, Washington. 
WHC-SD-CP-QAPP-018 Rev. 0

\subsection{BIBLIOGRAPHY}

Catlow, S. A., 1995, Method Performance for Radioanalytical Chemistry, WHC-SD-CP-LB-036, Westinghouse Hanford Company, Richland, Washington.

Clean Air Act of 1977, 42USC 7401 et seq.

Clean Water Act of 1977, 33 USC 1251 et seq.

Comprehensive Environmental Response, Compensation, and Liability Act of 1980, 42 USC 9601 et seq.

Currie, L. A., 1968, "Limits for Qualitative Detection and Quantitative Determination," Analytical Chemistry, 40(3):586-593.

David, Howard, 1984, Guidelines for Screening National Pollution Discharge Elimination System Permits.

DOE/RL, 1995, Hanford Analytical Services Quality Assurance Plan, DOE/RL-94-55, U.S. Department of Energy, Richland, Washington.

Ecology, EPA, DOE, 1994, Hanford Federal Facility Agreement and Consent Order, Vol. 1 and 2, Washington State Department of Ecology, Olympia, Washington; U.S. Environmental Protection Agency and U.S. Department of Energy, Washington, D.C.

EPA, 1977, Environmental Protection Agency National Emission Standards for Hazardous Air Pollutants, U.S. Environmental Protection Agency, Office of General Enforcement, Washington, D.C.

EPA, 1991, USEPA Contract Laboratory Program, Statement of Work for Organics Analysis, OLM02.1, U.S. Environmental Protection Agency, Washington, D.C.

Meznarich, H. K., 1994, Quality Assurance Program Plan for Laboratory Analyses and Process Testing, WHC-SD-CP-QAPP-003, Rev. 1, Westinghouse hanford Company, Richland, Washington.

Moss, S. S., 1992, Quality Assurance Project Plan for the Chemical Analysis of Highly Radioactive Samples in Support of Environmental Activities on the Hanford Site, WHC-SD-CPQAPP-002, Westinghouse Hanford Company, Richland, Washington.

Occupational Safety and Health Act of 1970, 21 USC 651 et seq.

Taylor, L. H., 1993, Analytical Chemistry Services Laboratories Quality Assurance Plan, WHC-SD-CP-QAPP-001, Westinghouse Hanford Company, Richland, Washington. 
WHC-SD-CP-QAPP-018 Rev. 0

Taylor, L. H., 1994, Quality Assurance Project Plan for the Chemical Analysis of Highly Radioactive Samples in Support of Environmental Activities on the Hanford Site, WHC-SD-CP-QAPP-002 Rev 0B, Westinghouse Hanford Company, Richland, Washington.

Westinghouse Hanford Company Analytical Services procedures:

LC-400-001, FORTRAN Coding and Documentation Guidelines

LC-400-002, Programmable Calculator Documentation and Coding Guidelines

LC-400-003, Basic Coding and Documentation Guidelines

LC-400-006, Spreadsheet Documentation Guidelines

LC-708-001, MULTI-LIMS Use in the Laboratory

LC-718-001, Laboratory ADP Systems Operations

LO-080-116, Glassware Cleaning for Standards Laboratory

LO-120-101, Proper Labeling and Recertification of Chemicals, Standards, and Reagents at $222-S$

LO-140-004, Routine Use of Mettler Electronic Balances

LO-150-001, Laboratory Measurement Quality Control Using Laboratory Measurement Control System (LMCS)

LO-150-105, Safety and Housekeeping Inspections of the 222-S Laboratory Complex

LO-150-132, Sample Storage, Rooms $2 E$ and 2B, and 222-S Laboratory Hot Cells

LO-150-135, Sample Disposal Criteria

LO-190-101, Hood Decontamination - 222-S Analytical Laboratory

LQ-150-001, Laboratory Measurement Quality Control

LQ-510-113, Calibration of Volumetric Dispensers

LQ-510-114, Calibration of Motor-Driven Burets

LQ-510-123, Calibration of Pipettors used in 222-S Laboratory 
WHC-SD-CP-QAPP-018 Rev. 0

Westinghouse Hanford Company Controlled Manuals:

WHC-CM-1-4, Corrective Action Management Manual 
WHC-SD-CP-QAPP-018 Rev. 0

APPENDIX A. QUALITY ASSURANCE INDEX

\begin{tabular}{|c|c|c|}
\hline QUALITY ASSURANCE REQUIREMENTS & DOCUMENTS - WHC & $\begin{array}{l}\text { PROCEDURES - } \\
\text { LABORATORY }\end{array}$ \\
\hline 1. Introduction & NA & NA \\
\hline 2. Organization and Responsibility & WHC-CM-4-2, QI 2.1 & \\
\hline 3. Personnel Qualification and Training & WHC-CM-4-2, QI 2.6 & WHC-CM-5-4. Sec. 4.0 \\
\hline $\begin{array}{l}\text { 4. Quality Assurance Objectives } \\
\text { 1. Data quality objectives } \\
\text { 2. Client data quality requirements }\end{array}$ & & $\begin{array}{l}\text { Client's QAPjP, } \\
\text { State of Work }\end{array}$ \\
\hline $\begin{array}{l}\text { 5. Systems Quality Assurance } \\
\text { 1. Software systems } \\
\text { 2. Administrative systems } \\
\text { 3. Physical facilities systems }\end{array}$ & $\begin{array}{l}\text { WHC-CM-4-2, QR } 19.0 \\
\text { WHC-CM-5-4 } \\
\text { WHC-SD-CP-HIE-001 }\end{array}$ & $\begin{array}{l}\text { WHC-SD-WM-CM-002 } \\
\text { Specific LC procedures } \\
\text { WHC-CM-5-4 } \\
\text { Specific LO procedures }\end{array}$ \\
\hline $\begin{array}{l}\text { 6. Sample Custody and Handling } \\
\text { 1. Chain of custody definition } \\
\text { 2. Holding times } \\
\text { 3. Sample receiving procedure } \\
\text { 4. Sample log-in and tracking procedure } \\
\text { 5. Laboratory internal chain-of-custody } \\
\text { 6. Sample disposal }\end{array}$ & & $\begin{array}{l}\text { LO-090-101-USQ } \\
\text { LO-090-101-USQ } \\
\text { LO-090-101-USQ } \\
\text { LO-090-101-USQ } \\
\text { Specific LO Procedures }\end{array}$ \\
\hline 7. Calibration & $\begin{array}{l}\text { WHC-CM-4-2, QR 12.0, QI 12.0, } \\
12.2,12.3,12.4,12.5,12,6,12.7\end{array}$ & $\begin{array}{l}\text { Specific LA procedures. letter of } \\
\text { instruction, statement of work, SD }\end{array}$ \\
\hline 8. Laboratory Procedures & & $\begin{array}{l}\text { WHC-CM-5-4, Sec } 3.9 \\
\text { WHC-CM-5-4, Sec } 3.10\end{array}$ \\
\hline 9. Data Collection, Reduction, and Reporing & & Test plan. letter of instruction, or SD \\
\hline 10. Records & WHC-CM-3-5. Sections 5.0 and 9.0 & \\
\hline 11. Quality Control & & $\begin{array}{l}\text { Specific test plan, letter of instruction, } \\
\text { or SD }\end{array}$ \\
\hline 12. Procedures to Assess Data Quajity & & Test plan or letter of instruction \\
\hline 13. Audits & WHC-CM-4-2, QR 18.0 & \\
\hline 14. Preventive Maintenance & & WHC-CM-5-4, Section 10.1 \\
\hline 15. Corrective Actions & $\begin{array}{l}\text { WHC-CM-4, QR 16.0, QI } 16.0 \text { - } \\
16.2\end{array}$ & WHC-CM-5-4, Chapters $6 \& 8$ \\
\hline \multicolumn{3}{|l|}{ 16. Quality Assurance Reporting } \\
\hline \multicolumn{3}{|l|}{ 17. Data Validation } \\
\hline 18. Procurement Planning & $\begin{array}{l}\text { WHC-CM-2-1 } \\
\text { WHC-CM-4-2, QR } 4.0\end{array}$ & \\
\hline
\end{tabular}


WHC-SD-CP-QAPP-018 Rev. 0

\section{APPENDIX B. ANALYTICAL OPERATIONS ORGANIZATION AND QUALITY INTERFACE}

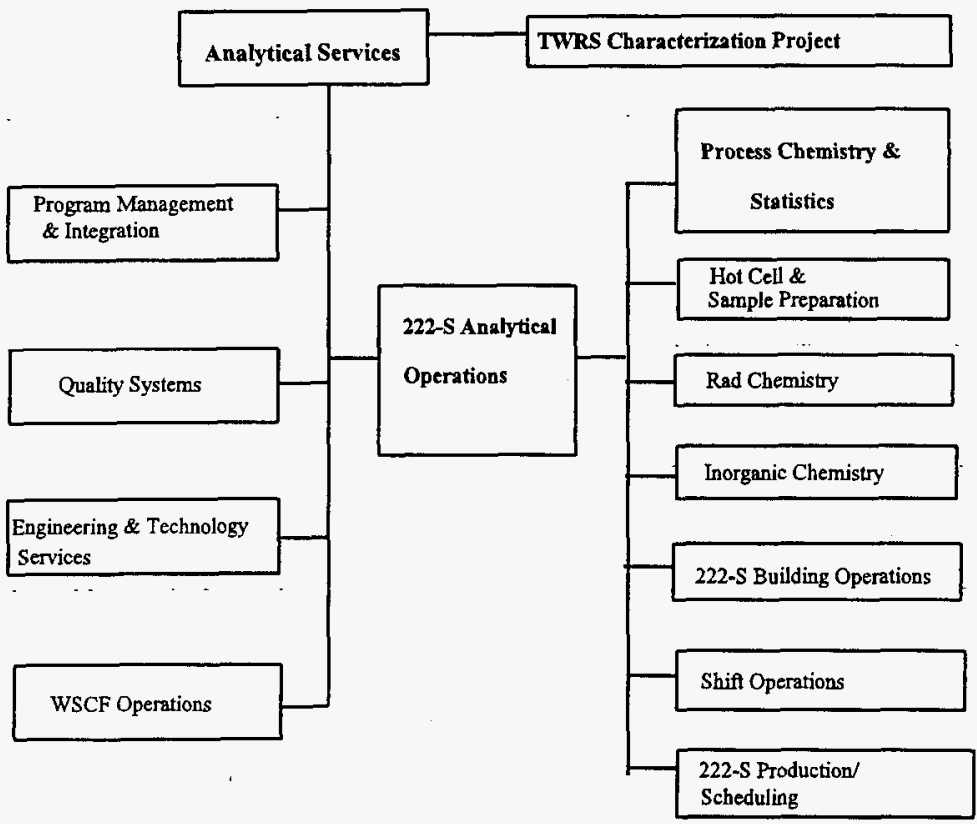

B-1 
WHC-SD-CP-QAPP-018 Rev. 0

This page intentionally left blank.

B-2 


\section{APPENDIX C. GLOSSARY}

accuracy

analyst

analyte

anomalies

assessment

client

comparability

completeness

consensus standard

continuous quality improvement degree of agreement of a measurement (or an average of measurements of the same thing), $\mathrm{X}$, with an accepted reference or true value, $\mathrm{T}$.

Accuracy is usually expressed as the difference between the two values, $\mathrm{X}$ - $T$, or the difference as a percentage of the reference or true value, 100 $(\mathrm{X}-\mathrm{T}) / \mathrm{T}$, and sometimes expressed as a ratio, $\mathrm{X} / \mathrm{T}$. Accuracy is a measure of the bias in a system.

person performing a measurement.

element, isotope, specie, or characteristic of a measurement.

something different, abnormal, or peculiar, not easily classified.

act or instance of assessing (appraisal); the act of reviewing, inspecting, testing, checking, conducting surveillance, auditing, or otherwise determining and documenting whether items processes or services meet specified requirements.

The terms assessment and verification as used in DOE Order 5700.6C are synonymous; their use is determined by who is performing the work. Assessments are performed by or for senior management. Verifications are performed by the line organizations.

For data, assessment encompasses verification and validation. Data assessment (verification and/or validation) can be performed within the laboratory and/or by an independent review agency at the discretion of the client to the criteria of the project.

person or organization submitting work.

expresses the confidence with which one data set can be compared to another.

measure of the amount of valid data obtained from a measurement system compared to the amount that was expected to be obtained under correct normal conditions.

procedure, protocol, or guidance document issued by a professional organization based on extensive testing and peer review.

program or system that monitors performance, evaluates trends, and implements changes based on trends. 
false negatives

false positive

matrix

nonconformance

out-of-control

(QC Failure)

precision

preventive

maintenance

qualify

quality assurance

reagent quality

regulatory

procedures

representativeness

traceable term that identifies the acceptance of a test or condition as false, when in fact it is true.

term that identifies the acceptance of a test or condition as true, when in fact it is false.

component or substrate (e.g., surface water, drinking water) that contains the analyte of interest.

deficiency in characteristic, documentation, or procedure that renders the quality of an item or activity unacceptable or indeterminate.

system is said to be out-of-control when it fails to meet preselected performance criteria.

measure of mutual agreement among individual measurements of the same property, usually under prescribed similar conditions. Precision is best expressed in terms of the standard deviation. Various measures of precision exist depending upon the prescribed similar conditions.

program of instrument care based on scheduled activities and spare parts inventory designed to minimize instrument downtime.

to qualify laboratory staff or a subcontractor is to provide evidence of meeting a performance standard for fitness by training skill or ability for a designated purpose. To qualify analytical procedures or computer programs is to provide evidence of performance to meet the required standard criteria.

the total integrated program for ensuring the reliability of monitoring and measurement data. Quality assurance is a system for integrating the quality planning, quality assessment, and quality improvement efforts to meet user requirements.

an analysis or industry-accepted grade that denotes purity or applicability for application.

those methods published or promulgated for laboratory use to meet the requirement of a law or government rule.

expresses the degree to which data accurately and precisely represent a characteristic of a population, parameter variations at a sampling point, a process condition, or an environmental condition.

document trail that identifies the history of a sample, standard, or other material. 
valid

validation

verification

verifying having legal efficacy or force, well grounded, or justifiable being at once relevant, meaningful, logically, and correct, appropriate to the end in view.

an act, process, or instance of validating. For data, validation is the process by which the data and quality control information is assessed or compared against the client's requirements.

act or process of verifying. For data, verification is the process of comparing the reported data with the required information.

to establish the truth, accuracy, or reality. 
DISTRIBUTION SHEET

\begin{tabular}{|c|c|c|c|c|c|}
\hline \multirow{2}{*}{$\begin{array}{l}\text { To } \\
\text { Distribution }\end{array}$} & \multirow{2}{*}{\multicolumn{3}{|c|}{$\begin{array}{l}\text { From } \\
\text { H. K. Meznarich }\end{array}$}} & \multicolumn{2}{|l|}{ Page 1 of 1} \\
\hline & & & & \multicolumn{2}{|c|}{ Date $6 / 26 / 96$} \\
\hline \multirow{2}{*}{\multicolumn{4}{|c|}{ Project Title/Work Order }} & \multicolumn{2}{|c|}{ EDT No. $-602183 \quad 6 / 218$} \\
\hline & & & & \multicolumn{2}{|l|}{ ECN No. } \\
\hline Name & MSIN & $\begin{array}{l}\text { Text } \\
\text { With All } \\
\text { Attach. }\end{array}$ & Text Only & $\begin{array}{l}\text { Attach./ } \\
\text { Appendix } \\
\text { Only }\end{array}$ & $\begin{array}{l}\text { EDT/ECN } \\
\text { Only }\end{array}$ \\
\hline
\end{tabular}

U. S. Department of Energy, RL

C. A. Babel

57-54 $x$

R. P. Carter

S7-55 $X$

P. K. Clark

S7-55 $X$

K. K. Kawabata

S7-55 $X$

Westinghouse Hanford Company

G. B. Griffin

T6-16 $X$

D. W. Hendrickson

L5-31 $x$

J. E. Hyatt

S3-30 $x$

J. R. Jewett (6)

T6-09 $X$

A. G. King

T6-03 $X$

H. K. Meznarich (3)

S3-30 $x$

C. T. Narquis

T6-16 X

Central Files (1)

A3-88 $X$

